\title{
Evaluating and comparing entrepreneurial ecosystems using SMAA and SMAA-S
}

\author{
Salvatore Corrente ${ }^{1}$, Salvatore Greco ${ }^{1,2}$, Melita Nicotra $^{1}$, Marco Romano $^{1}$, Elita Schillaci ${ }^{1}$ \\ ${ }^{1}$ Department of Economics and Business, University of Catania, Corso Italia, 55, 95129 Catania, Italy \\ ${ }^{2}$ University of Portsmouth, Portsmouth Business School, Centre of Operations Research and Logistics (CORL), \\ Richmond Building, Portland Street, Portsmouth PO1 3DE, United Kingdom
}

\begin{abstract}
This paper focuses on the entrepreneurial ecosystem as a set of interdependent and coordinated factors in a territory enabling entrepreneurship. To date, academic research has failed to produce methodologies for evaluating and comparing entrepreneurial ecosystems from different perspectives that can highlight the underlying factors. Moreover, there is a lack of empirical analysis that discriminates between factors according to their importance. Taking into account these two gaps, the aim of the paper is twofold. First, it proposes the application of an accurate, robust and reliable measurement technique, namely Stochastic Multicriteria Acceptability Analysis (SMAA). It considers the variability of weights that can be assigned to the different factors, producing a probabilistic ranking to obtain a comparison among entrepreneurial ecosystems. This ranking is more reliable than a single ranking proposed by the usual composite indices that take into account a single vector of weights. Second, the paper presents a new methodology, SMAA for strategic management analytics and assessment, or SMAA squared (SMAA-S), which detects the relation between entrepreneurial ecosystem factors and growth-oriented start-ups in a territory. The results show that the most relevant entrepreneurial ecosystem factors enabling the birth and activity of high-growth start-ups, and so impacting on technology, economy and society, can be identified in cultural and social norms, government programs, and internal market dynamics.
\end{abstract}

Keywords Entrepreneurial ecosystem, Stochastic Multicriteria Acceptability Analysis, Strategic management analytics and assessment, Start-ups

\section{Introduction}

Increasing attention is being paid to the theme of "entrepreneurship" in both the political and academic domains. Numerous countries promote start-ups because they create jobs, reducing unemployment, and they generate innovation, explore new markets, and define the way to provision of jobs in the future; they are also a way of commercializing new ideas and technologies. In general, promoting productive entrepreneurship increases competition, boosting the efficiency of a market and improving people's welfare (Fischer and Nijkamp 1988; Sternberg 2012).

One emerging approach in the entrepreneurship literature is a focus on entrepreneurial ecosystems, defined as a set of interdependent actors and factors of a territory coordinated in such a way that enables entrepreneurship (Cohen 2006; Cunningham and O'Kane 2017; Feld 2012; Isenberg 2010; Malecki 2011; Napier and Hansen 2011; Neck et al. 2004; Van de Ven 1993; Zacharakis et al. 2003). New firms also emerge because their environment, or ecosystem, facilitates their activity (Audretsch and Belitski 2017; Carayannis et al. 2016; Schillaci and Nicotra 2010). Therefore, the entrepreneurial ecosystem approach focuses on the external business environment that facilitates the birth of new firms.

Government and non-government agencies, venture capitalists, and business consultants have paid considerable attention to "measuring" entrepreneurial ecosystems. Institutions such as the World Bank, the World Economic Forum (WEF), and the Organization for Economic Co-operation and Development (OECD) have developed comprehensive diagnostic tools for ranking entrepreneurial ecosystems. Indeed, "measuring" entrepreneurial ecosystems in order to "compare" them is a focal point. Ad hoc methods for making useful comparisons, with scientific and academic validity, are needed to help nations, sub-national regions, and cities realize their strengths and weaknesses, thus enabling them to understand how to shape their own entrepreneurial ecosystem. However, academic research has failed to keep up with benchmarking entrepreneurial ecosystems as 
an element in guiding national competitiveness. This is due to several issues, both technical and conceptual. In particular, no rigorous studies have been conducted concerning methodologies for "comparing" entrepreneurial ecosystems, such as those on which practitioners are currently focused.

To fill this gap, the paper proposes the application of an accurate, robust, and reliable measurement technique, namely Stochastic Multicriteria Acceptability Analysis (SMAA; Lahdelma et al. 1998). By applying SMAA methodology, we offer a substantial contribution to achieving robust evaluation of entrepreneurial ecosystems, and ranking and comparing them. Generally, when comparing and ranking different countries some form of composite index is adopted, based on the arithmetic mean of certain factors of interests (for a recent survey on composite indices, see Greco et al. 2018). Very often no weights are considered in computing the mean; that is, the factors are equally weighted. More rarely some weighted mean is considered to assign a different level of importance to the factors considered. In this case, the choice of the weights to be assigned to each factor (e.g., finance system, government policy, entrepreneurial university, education system) of the entrepreneurial ecosystem is a crucial step since different weight vectors can provide different rankings of the countries, and thus different results can be obtained from the analysis of the same data. This is reasonable because different weights imply different perspectives from which different implications can be drawn. However, establishing the weights of the factors considered is always arbitrary to some extent, and, consequently, a more objective approach that makes it possible to take into account the potential for different viewpoints would be beneficial for the comprehensive value of the results obtained from the data analysis.

From this perspective, SMAA avoids the arbitrary choice of weights by considering all feasible vectors of weights and their corresponding rankings. From an operational point of view, the consideration of all feasible weight vectors is approximated by the random sampling of a large number of weight vectors. For example, in the analysis presented here, we considered samples of 1,000,000 weight vectors extracted with a uniform distribution. Consideration of all the weight vectors permits SMAA to supply a more realistic ranking of countries. Indeed, it is rather misleading to assign a well-defined and stable ranking position to each country when this essentially depends on the importance assigned to each factor through the corresponding weight. In this regard, it is much more reliable to consider a probabilistic ranking that assigns a probability of each ranking position being attained. Moreover, SMAA reveals the strengths and weaknesses of each country in terms of the various factors, with a larger weight indicating a better or worse ranking position. This gives relevant indications to academics, policymakers, and practitioners, especially in terms of policy implications.

Apart from the focus of agencies and consultants on measuring entrepreneurial ecosystems, the recent literature on entrepreneurial ecosystems considers the definition of which factors are the most important for the entrepreneurial success of ecosystems. Among others, Van de Ven (1993), Cohen (2006), Isenberg (2011), and Feld (2012) have provided some lists of relevant elements characterizing effective entrepreneurial ecosystems. Such literature is largely based on the direct experiences of researchers, and does not empirically embrace the relation between ecosystem factors and growth-oriented start-ups in a territory.

As emphasized by various authors (see Alvedalen and Boschma 2017; Stam 2015; Stam and Spigel 2017), the relation between the factors of an ecosystem and their output- that is the number of growth-oriented startups- has not been empirically investigated in depth.

While SMAA can provide interesting insights in terms of the performance of different countries expressed as the probability of ranking position, and can indicate weaknesses and strengths, it does not offer any support with respect to inferences concerning the relevance of the factors for the outputs of the countries. Currently, SMAA methodology cannot lend any support in dealing with this question: what are the most important factors determining the success of a country in terms of the number of start-ups? The answer entails defining a theory related to the phenomenon under analysis and deriving suitable policy implications.

Based on SMAA, we thus propose a novel technique, namely SMAA for strategic management analytics and assessment, or SMAA squared (SMAA-S), which output is a "theory" defining different importance factors permitting to explain the phenomenon under investigation. The starting point is that each possible theory can be viewed as a rank ordering of the factors from the most important to the least important. Therefore, for each theory, we can consider a sampling of the set of weight vectors with a value in respect of the importance assigned to the factors by the theory. This means that if factor A is more important than factor B, and the latter is more important than factor $\mathrm{C}$, the weight of $\mathrm{A}$ is greater than the weight of $\mathrm{B}$, and this in turn is greater than the weight of C. For each theory, that is for each different ranking of factors, we can compute the barycenter of the corresponding set of weights. Within this framework, it is natural to say that one theory is better than another, or 
that one ranking of the importance of factors is better than another, if it represents in a more optimal manner the success of a country as represented by an exogenous indicator used as a proxy. This can be measured by means of the Kendall (1938) tau correlation coefficient, computing the number of inversions between two rankings: (i) the ranking of countries with respect to the exogenous indicator, and (ii) the ranking supplied by the composite index with the weights corresponding to the barycenter of the weight vectors related to a given order of the importance of factors. The importance ranking presenting the maximum Kendall's tau corresponds to the optimal theory. Thus, if for the importance ranking with the maximum Kendall's tau factor A is more important than factor $\mathrm{B}$, and this in turn is more important than factor $\mathrm{C}$, we have to conclude that the optimal theory is the one for which $\mathrm{A}$ is more important than $\mathrm{B}$, and $\mathrm{B}$ is more important than $\mathrm{C}$. We applied the SMAA-S methodology to the performance of European countries in terms of entrepreneurial ecosystems, considering as a proxy the number of growth-oriented start-ups.

To the best of our knowledge, our application of SMAA and SMAA-S is the first study on the subject based on data analysis. We observe how the results provided by both methodologies are complementary in designing a policy that can be modeled through two antecedents: (i) the enhancement of the relative advantages, taking into consideration the ranking and the comparisons of countries with respect to the different roles and weights assigned to the considered factors based on SMAA; (ii) the strengthening of the factors that have been shown to be the greatest determinants of the performance of the countries as inferred from the empirical evidence supplied by the available data based on SMAA-S.

The methodology proposed in the paper provides interesting results. First, SMAA shows that each country has its specific weaknesses and strengths, and the greater the weight of strengths and the lower the weight of weaknesses for a country indicates that it compares better with other countries. Second, SMAA-S shows, based on the available data, that the most relevant entrepreneurial ecosystem factors enabling the birth and activity of high-growth start-ups lie in cultural and social norms, government programs, and internal market dynamics. Each country has to define a policy looking at its strengths and weaknesses, as well as the factors demonstrated on average to be the greatest determinants in pushing the presence of high-growth start-ups.

The remainder of the paper is organized as follows. In section 2 we review the related literature and present the objectives of our research. Section 3 describes the SMAA methodology as well as the new proposal, SMAA$\mathrm{S}$, by means of a didactic example. In section 4 we introduce the case study, describing the data used in our analysis. Section 5 contains the results of the application of the new proposed methodologies. Finally, in the last section we provide some conclusions and highlight future research avenues.

\section{Theoretical considerations}

Adopting the entrepreneurial ecosystem approach recognizes that new firms emerge and grow because they are located in an environment or ecosystem that facilitates the activities of visionary individuals (Audretsch and Belitski 2017; Carayannis et al. 2016; Chapman 2011; Cohen 2006; Feld 2012; Isenberg 2010; Malecki 2011; Napier and Hansen 2011; Neck et al 2004; Van de Ven 1993; Zacharakis et al. 2003). The entrepreneurial ecosystem approach, as in other established concepts, such as industrial districts, clusters, and innovation systems, focuses on the external business environment. However, it is different from these, because it deals solely with entrepreneurs and start-ups as unique organizational entities with different capabilities and resources, and on the role of the social and economic contexts surrounding entrepreneurial processes. Specifically, the concept of the ecosystem applied to entrepreneurship relates to the capacity of a territory to create a system of actors and infrastructures supporting the creation and development of innovative business projects, beyond the mere construction of a network structure between companies. It refers to a broad system of heterogeneous elements.

Van de Ven (1993) suggests that the historical focus of researchers on entrepreneurs has led to a lack of appreciation for the activities of multiple actors. Therefore, a definition that seems widely applicable is that of the entrepreneurial ecosystem as comprising a set of interdependent actors and factors coordinated in such a way that enables productive entrepreneurship. New value in society is the ultimate outcome of an entrepreneurial ecosystem, while entrepreneurial activity is rather an intermediary output of the system. Entrepreneurial activity has many manifestations, such as innovative start-ups, high-growth start-ups, and entrepreneurial employees. There are factors that characterize an ecosystem, making it a habitat suitable for certain economic activities, such as the availability of real and potential know-how, and the presence of investors, human resources, culture, 
infrastructure, institutions, regulatory and fiscal conditions, social and environmental quality, and the ability to generate innovation.

The process of developing an enabling ecosystem for entrepreneurial events has received considerable attention from non-academic organizations. As stated, government and non-government agencies, as well as consultants, have placed emphasis on "measuring" entrepreneurial ecosystems, applying various methodologies. The OECD conceptualizes the entrepreneurial ecosystem as determined by the presence of a regulatory framework, market conditions, access to finance, the creation and diffusion of knowledge, entrepreneurial capabilities, and an entrepreneurial culture. ${ }^{1}$ The OECD (2016) publication "Entrepreneurship at glance" presents a collection of international data on such entrepreneurial ecosystem factors for around 50 countries based on official government statistical sources. The OECD does not consider a single composite index but presents a set of indicators:

"A defining characteristic of the program is that it does not provide a single composite measure of overall entrepreneurship within an economy. Rather, recognizing its multi-faceted nature, the program revolves around a suite of indicators of entrepreneurial performance that each provides insights into one or more of these facets." (OECD, 2016, p. 9)

In addition, the Babson Entrepreneurship Ecosystem Project provides a framework categorized into six domains, in line with Isenberg's (2011) theorization: government regulations supporting entrepreneurship; finance; entrepreneurial culture; physical infrastructure; human capital and markets as entrepreneurial networks; the presence of early customers. ${ }^{2}$ Babson College supports the realization of the Global Entrepreneurship Monitor (GEM) reports. Through the National Experts Survey (NES), GEM obtains internationally comparable data on environmental factors related to new firm creation. As in the work of the OECD, GEM does not propose a single metric but a range of indicators, overcoming the weighting issue. This choice comes at the cost of renouncing a single unified view in favor of a range of indicators that is more difficult to communicate. In its "Global Competitiveness Report", the $\mathrm{WEF}^{3}$ assesses the ecosystem competitiveness of 144 economies, providing insight into their drivers. The components are grouped into 12 factors of ecosystem competitiveness: institutions, infrastructure, the macroeconomic environment, health and primary education, higher education and training, goods market efficiency, labor market efficiency, financial market development, technological readiness, market size, business sophistication, and innovation. Measures are reported for the 12 factors separately, but factors are also aggregated into a single index.

From the academic point of view, recent literature has provided several theories showing which factors, among others, are judged important for the success of an entrepreneurial ecosystem. Van de Ven (1993) describes in detail the industrial infrastructure facilitating new firm creation. Such infrastructure includes institutional arrangements for regulating and standardizing a new technology, public resource endowments of basic scientific knowledge, financing mechanisms, a pool of competent labor, proprietary research and development (R\&D), manufacturing, marketing, and distribution functions. Neck et al. (2004) and Cohen (2006) consider as key components of entrepreneurial ecosystems informal networks, formal networks, universities, governments, professional and support services, capital services, and the talent pool. Isenberg (2011) proposes a model for entrepreneurial ecosystems composed of elements that can be grouped into six domains: conducive culture, facilitating policies and leadership, availability of dedicated finance, relevant human capital, venturefriendly markets for products, and a wide set of institutional and infrastructural supports. Feld (2012) emphasizes the interaction between the players in the ecosystem (a strong group of entrepreneurs, mentors, advisors, and a strong network) and access to all types of relevant resources (talent, services, capital) in a context of an enabling government. Spigel (2017) has argued that an entrepreneurial ecosystem is composed of 11 cultural, social, and material attributes that provide benefits and resources to entrepreneurs. These are the following: a supportive culture, a history of entrepreneurship, worker talent, investment capital, networks, mentors and role models, policy and governance, universities, support services, physical infrastructure, and an open market.

\footnotetext{
${ }^{1}$ http://www.oecd.org/industry/business-stats

${ }^{2}$ http://entrepreneurial-revolution.com

${ }^{3}$ http://www.weforum.org
} 
Thus, the literature has defined lists of relevant entrepreneurial ecosystem factors, without any clear empirical evidence. Such lists have largely been based on the direct experiences of researchers without empirically embracing the link between entrepreneurial ecosystem factors and new venture creation (Cohen 2006; Isenberg 2011; Feld 2012; Neck et al. 2004; Spigel 2017). For example, Isenberg (2011) states:

“...I draw on decades of experience around the world, as well as my own as an entrepreneur, academic, venture capitalist, angel investor, government advisor (including playing a small role advising the White House's Start-up America). I also lived in Israel for 22 years and participated in the miraculous entrepreneurial transformation of that society."

Moreover, the introduction to the book "Start-up communities: building an entrepreneurial ecosystem in your city" by Feld (2012) states:

"Based on more than 20 years of Boulder-based entrepreneur turned venture capitalist Brad Feld's experience in the field, as well as contributions from other innovative start-up communities, this reliable resource skillfully explores what it takes to create an entrepreneurial community in any city, at any time."

Other studies on entrepreneurial ecosystems are based on single regional case studies. For example, Cohen (2006) refers to the region of Victoria, British Columbia, and discusses its potential to achieve a sustainable entrepreneurial ecosystem, while Neck et al. (2004) refer to the region of Boulder, Colorado.

Actually, a certain part of literature sustains that only qualitative research can understand entrepreneurship as "a complex social phenomenon in a particular spatial and temporal context" and "characterized by complex, dynamic and emergent processes, and the interplay between actors, processes, and contexts" (Karatas- Ozkan et al. 2014, p. 590). Similarly, Roundy et al. (2017) assert that "count- based" metrics do not adequately capture the unequal importance of actors and processes over time and that we need more narrative accounts of entrepreneurial ecosystems.

However, as point out by Audretsch and Belitski (2017) "methodologically it is important to develop metrics in order to determine the strengths and weaknesses of a regional system of entrepreneurship and the relationship between each domain of the system, so that most relevant components can be assessed and targeted". Besides, Harrington, 2016 states that "one aspect of ecosystem measurement relates to the ability to compare the effectiveness of different ecosystems. It is important that individual regions have a barometer to measure how their specific ecosystem is progressing and its level of momentum".

In line with this, the first aim of this paper is to define an appropriate method to enable useful comparisons among entrepreneurial ecosystems. A method that has scientific and academic validity in comparing ecosystems is needed to help nations and sub-national regions realize their strengths and weaknesses, and thus to understand how to shape their own entrepreneurial ecosystems. Academic research has not focused to any great extent on the analysis of the performance of entrepreneurial ecosystems as an element to guide national competitiveness. Nonetheless, performance measures and the comparison of entrepreneurial ecosystems are significant in both designing and evaluating policies that support entrepreneurship. Accurate, robust, and reliable measurements and comparison techniques are critical in improving the accountability and appraising the efficiency of devolved European nations. This aspect assumes even more importance in the European system in which resource allocation is dependent on countries' performance at all levels (European Commission, 2013). No rigorous studies have been carried out on methodologies for comparing entrepreneurial ecosystems. To develop a comparison, we present a specific methodology based on SMAA (Lahdelma et al. 1998).

SMAA makes it possible to progress from a misleading single well-defined ranking for which each country has a single clear-cut ranking position, ignoring dependence on the weight vector adopted, to a fair and honest probabilistic ranking in which each country has only a probability of having one ranking position, keeping explicitly and clearly in mind the fact that the ranking position depends on the weight vector adopted. This avoids the risk of becoming trapped in a partial and reductive representation offered by an aggregation of the different factors in which a single perspective is considered represented by a specific vector of weights, and, even worse, no vector of weights is employed, thus giving artificial and misleading equal importance to all the factors identified. Instead, looking at the ranking of countries from different perspectives makes it possible to 
view them on a more comprehensive basis, and this reveals the strengths and weaknesses of each country in terms of competitive advantage.

Another point worthy of discussion with respect to entrepreneurial ecosystems is the definition of a theory that, on the basis of empirical evidence, explains the role of different factors in the entrepreneurial performance of a given country. The relation between entrepreneurial ecosystems and growth-oriented start-ups has not been studied in depth. Stam $(2015$, p. 8) asserts that "entrepreneurial ecosystem factors do provide some focus, but they offer no consistent explanation of their coherence or their interdependent effects on entrepreneurship and, ultimately, on aggregate welfare." Stam and Spiegel (2017) argue that the first issue with the entrepreneurial ecosystem literature relates to the fact that it does not measure the relation between entrepreneurial ecosystem factors and entrepreneurship activity in a territory. Moreover, Alvedalen and Boshma (2017) emphasize the lack of clear analytical studies that explicitly link cause and effect in entrepreneurial ecosystems.

Recently, an effort has been made in this direction by Audretsch and Belitski (2017) demonstrating the impact of both regional context, proxied by the REDI Index, and the local context proxied by the framework conditions of the ecosystem (culture, formal institutions, infrastructure and amenities, IT, Melting Pot and demand) on start-ups rate in cities, using exploratory factor analysis and structural equation modelling. Another study by Carayannis et al. (2016) examines and validate, through an agent-based simulation model, how the institutional context of a region influences new ventures' knowledge acquisition and in turn the level of sustained entrepreneurial activity within the region,.

In this debate, we approached this point with a novel technique, SMAA-S, that we are proposing in the same line as the SMAA philosophy. In developing and applying SMAA-S, we analyze the most critical factors of an entrepreneurial ecosystem affecting the presence of growth-oriented start-ups. As previously observed, the ranking of entrepreneurial ecosystems is strictly dependent on the importance assigned to the factors considered. Therefore, we take into account the plurality of rankings by means of the following two-step procedure:

1. We consider all possible rankings of importance for the entrepreneurial ecosystem factors and we select one representative weight vector for each; then we compute the corresponding rankings of European countries.

2. We pick the importance rankings for which the corresponding rankings of countries are more correlated according to the Kendall tau with the ranking given by the presence of high-growth start-ups.

The importance rankings presenting the highest correlation provides information on the most relevant factors of an entrepreneurial ecosystem.

\section{Methods}

In multiple criteria decision analysis (MCDA; see Greco et al. 2016 for an updated collection of state-of-the-art surveys on MCDA), a set of alternatives $A=\left\{a_{1}, \ldots, a_{n}\right\}$ is evaluated with respect to a coherent family of aspects (technically called criteria) (Roy 1996) to deal with a choice, ranking, or sorting problem. In this paper, we consider a ranking problem in which 24 entrepreneurial ecosystems in Europe are the alternatives considered, and the criteria are the 12 factors on which these countries are evaluated. Looking at the evaluations of the alternatives for the criteria considered, the only objective information that can be gathered is the dominance relation, where $a_{h}$ dominates $a_{k}$ if $a_{h}$ is at least as good as $a_{k}$ for all criteria and better for at least one criterion. In any case, the objectivity of this relation has as a counterpart its poverty, since in comparing two alternatives, it is often the case that one is preferred over the other on some criteria, while the opposite is true in other cases. For this reason, evaluations have to be aggregated to obtain a recommendation with respect to the problem at hand. Different aggregation methodologies can be considered in MCDA; among these, the best known are value functions (Keeney and Raiffa 1976), outranking methods (Roy 1996), and decision rules (Greco et al. 2001). In this work, we consider value functions. Value functions assign to each alternative a number, this being representative of its "goodness" with respect to the problem considered. If the evaluation criteria are preferentially independent (Keeney and Raiffa 1976), the value function can be written in an additive way:

$$
U\left(a_{h}\right)=\sum_{j=1}^{m} u_{j}\left(g_{j}\left(a_{h}\right)\right)
$$


where $u_{j}$ are monotone with respect to preferences for $g_{j} \in G$. In particular, in its simplest form, eq. (1) can be expressed as a weighted sum:

$$
U\left(a_{h}, w\right)=\sum_{j=1}^{m} w_{j} g_{j}\left(a_{h}\right)
$$

where $w_{j} \geq 0$ for all $j=1, \ldots, m$, and $\sum_{j=1}^{m} w_{j}=1$.

Despite its widespread application, the use of the weighted sum depends on two main points:

- The evaluations of the alternatives based on the criteria considered have to be expressed using commensurable scales.

- A single vector of weights $\left(w_{1}, \ldots, w_{m}\right)$ needs to be known in advance.

While the first issue is relevant in many applications and different authors have proposed several normalization techniques (see, e.g., Angilella et al. 2015, for a recent contribution on this topic), in this paper we are more interested in the second, namely that to use the weighted sum one needs to define a single vector of weights. The final recommendation concerning the problem considered is strictly linked to and dependent on this choice. However, choosing a vector of weights can only be considered arbitrary. To justify this statement, let us consider the following example.

SMAA removes the need for this choice by considering simultaneously a plurality of vectors of weights. Taking into account "all" vectors of weights, a probabilistic ranking of the alternatives is provided in terms of the frequency with which an alternative attains a certain rank position, or in terms of the frequency of the preference of an alternative over another. SMAA was first introduced in Lahdelma et al. (1998), and has since been widely used in MCDA, as witnessed by its many applications (e.g., Lahdelma et al. 2002; Tervonen et al. 2009). Other applications of the SMAA methodology in different research fields can be found in Tervonen and Figueira's (2008) survey.

The SMAA methodology is based on two probability distributions, $f_{W}(w)$ and $f_{\chi}(\xi)$, defined, respectively, based on the weights space $W=\left\{\left(w_{1}, \ldots, w_{m}\right) \in R^{m}: w_{j} \geq 0, \sum_{j=1}^{m} w_{j}=1\right\}$, and on the evaluation space $\chi=$ $\left[\xi_{k j}\right]_{k=1, \ldots,|A|}$, where $\xi \in \chi$ is one evaluation matrix. By using the notation $\xi_{k j}=g_{j}\left(a_{k}\right)$, eq. (2) can then be $j=1, \ldots, m$,

written as $U\left(a_{k}\right)=U\left(\xi_{k}, w\right)=\sum_{j=1}^{m} \xi_{k j} w_{j}$ for certain $\xi \in \chi$. For each $a_{k} \in A, w \in W$, and $\xi \in \chi$, SMAA computes the ranking position attained by $a_{k}$ using the following ranking function:

$$
\operatorname{rank}(k, \xi, w)=1+\sum_{h \neq k} \rho\left(U\left(\xi_{h}, w\right)>U\left(\xi_{k}, w\right)\right)
$$

where $\rho($ true $)=1$ and $\rho($ false $)=0$.

Moreover, for each $a_{k} \in A$ and $\xi \in \chi$, and for each rank position $r \in\{1, \ldots, n\}$, the subset of $W$ giving $a_{k}$ the $r$-th position in the ranking can be defined:

$$
W_{k}^{r}(\xi)=\{w \in W: \operatorname{rank}(k, \xi, w)=r\}
$$

The SMAA methodology is therefore based on the computation of the following indices:

- The rank acceptability index $b\left(a_{k}, r\right)$ gives the frequency with which alternative $a_{k}$ attains position $r$ in the final ranking:

$$
b\left(a_{k}, r\right)=\int_{\xi \in \chi} f_{\chi}(\xi) \int_{w \in W_{k}^{r}(\xi)} f_{\chi}(\xi) d w d \xi
$$

The best alternatives will be those presenting high values of $b\left(a_{k}, r\right)$ for high-ranking positions and small values of $b\left(a_{k}, r\right)$ for low-ranking positions. While the application of data envelopment analysis (DEA; Charnes et al. 1987) only indicates whether an alternative can be efficient or not, that is if it can attain the first position in the ranking or not, the computation of the rank acceptability index, $b\left(a_{k}, 1\right)$, provides more information. Indeed, a value $b\left(a_{k}, 1\right)=0$ means that $a_{k}$ is not efficient, while $b\left(a_{k}, 1\right)>$ 0 means not only that $a_{k}$ is efficient, but also gives the frequency with which this alternative can attain the best position. 
- The central weight vector $w^{c}\left(a_{k}\right)$ represents the average preferences of an individual giving to $a_{k}$ the best position and it is computed as the barycenter of the weight vectors in $W_{k}^{1}(\xi)$ :

$$
w^{c}\left(a_{k}\right)=\frac{1}{b\left(a_{k}, 1\right)} \int_{\xi \in \chi} f_{\chi}(\xi) \int_{w \in W_{k}^{1}(\xi)} f_{W}(w) w d w d \xi
$$

- The pairwise winning index $p_{h k}$ (Leskinen et al. 2006) measures the frequency with which $a_{h}$ is preferred over $a_{k}$ :

$$
p\left(a_{h}, a_{k}\right)=\int_{w \in W} f_{W}(w) \int_{\xi \in \chi: U\left(\xi_{h}, w\right)>U\left(\xi_{k}, w\right)} f_{\chi}(\xi) d \xi d w
$$

We should point out that relevant information, similar to the central weight vector, could be gathered by computing the barycenter of the weights giving to an alternative a position different from the first. For example, a policymaker could also be interested in the average weights giving to a certain alternative the second position, the third position, and so on, until the last position. For this reason, in our paper we have extended the central weight vector as follows:

$$
-\quad w^{c}\left(a_{k}, r\right)=\frac{1}{b\left(a_{k}, r\right)} \int_{\xi \in \chi} f_{\chi}(\xi) \int_{w \in W_{k}^{r}(\xi)} f_{W}(w) w d w d \xi
$$

The index in eq. (6) represents the average preferences giving to alternative $a_{k}$ the $r$-th position; so, $w^{c}\left(a_{k}, 1\right)=$ $w^{c}\left(a_{k}\right)$.

From a computational point of view, the multidimensional integrals in eqs. (3)-(6) are estimated by Monte Carlo simulations. This means that in an iterative way, different weight vectors and performance matrices are sampled from the corresponding spaces taking into account the distributions considered, $f_{W}(w)$ and $f_{\chi}(\xi)$. Then, for each weight vector and for each performance matrix, the corresponding ranking of the alternatives is computed. Finally, the rank acceptability indices and the pairwise winning indices are provided for each alternative, $a_{k} \in A$, and for each pair of alternatives, $\left(a_{h}, a_{k}\right) \in A \times A$, respectively.

In the application of the SMAA methodology that we are considering in this case, the evaluations of the alternatives are fixed, and therefore only the variability of the rankings with respect to the choice of the weight vectors will be analyzed.

As previously shown, the ranking of the alternatives will depend on the choice of the weights assigned to the criteria considered. Therefore, the application of the SMAA methodology permits the drawing of robust conclusions in terms of the frequency of attaining a certain ranking position, as well as in terms of the frequency of preference between alternatives.

As far as SMAA-S is concerned, it is a methodology developed here in order to apply the SMAA philosophy to certain specific issues in the strategic management field, and more generally to the inferencing of a theory from a set of available data. Suppose we want to build a theory to explain how certain factors $f_{1}, \ldots, f_{m}$ explain a variable $V$, that is, suppose we want to define which among the factors $f_{1}, \ldots, f_{m}$ is the most important, the second most important, the third most important, and so on, with respect to the value taken by $V$. In this framework, the basic points of SMAA-S are as follows:

1) A theory is intended as a ranking of the importance of factors considered.

2) The more important a factor, the greater the weight assigned to it.

3) Given two theories, A and B, represented by two vectors of weights, A is better than B if the similarity between the ranking of the alternatives obtained using the weights representing $A$ and the ranking of alternatives given by $V$ is greater than the similarity between the ranking of the alternatives obtained using the weights representing B and the ranking of alternatives given by $V$. 
4) We want to select the best theory, that is the ranking of the importance of factors $f_{1}, \ldots, f_{m}$ for which the corresponding vectors of weight give a ranking of alternatives more in accordance with the ranking given by the value of $V$.

Taking into account the above points, we can define the following methodology.

Looking at the alternative evaluations and taking into account a certain ranking of alternatives, $\operatorname{Rank}_{\text {Benchmark }}$, given by the variable to be explained $V$, one might wonder which is the criterial ranking (w.r.t. importance) giving the alternatives ranking closest to $\operatorname{Rank}_{\text {Benchmark }}$. Therefore, given $m$ criteria $g_{1}, \ldots, g_{m}$, we would like to discover which is the criterial ranking $g_{(1)} \succsim g_{(2)} \gtrsim \cdots \gtrsim g_{(m)}$ (where $g_{(1)}$ is the most important criterion, $g_{(m)}$ is the least relevant, and $g_{\left(j_{1}\right)} \succsim g_{\left(j_{2}\right)}$ means that $g_{\left(j_{1}\right)}$ is at least as important as $\left.g_{\left(j_{2}\right)}\right)$, such that the ranking of corresponding alternatives $R_{(\cdot)}$ is the closest to the ranking of alternatives Rank $_{\text {Benchmark }}$ that we would like to replicate. There is no single vector of weights in ranking the importance $g_{(1)} \succsim g_{(2)} \succsim \cdots \gtrsim g_{(m)}$. Thus, for each of these importance rankings, we select one representative vector of weights, this being the barycenter of the set of the vector of weights with the importance ranking considered, that is, the set of the vector of weights for which $w_{(1)}$ is greater than $w_{(2)}, w_{(2)}$ is greater than $w_{(3)}$, and so on. In greater detail, with $w_{(1)}, \ldots, w_{(m)}$ denoting the weights of criteria $g_{(1)}, \ldots, g_{(m)}$, the above criterial ranking is converted to the following inequalities chain:

$$
w_{(1)} \geq w_{(2)} \geq \cdots \geq w_{(m)}
$$

The inequalities in eq. (1) define a polyedron of weight vectors, the vertices of which are as follows (Paelinck 1974):

$$
\begin{gathered}
w^{(1)}=(1,0, \ldots, 0) \\
w^{(2)}=\left(\frac{1}{2}, \frac{1}{2}, \ldots, 0\right) \\
\ldots \ldots \ldots \\
w^{(m)}=\left(\frac{1}{m}, \frac{1}{m}, \ldots, \frac{1}{m}\right)
\end{gathered}
$$

Consequently, the barycenter $B W$ of the polyedron considered is the average, component by component, of the vectors $w^{(1)}, w^{(2)}, \ldots, w^{(m)}$, that is:

$$
B W=\frac{1}{m}\left(1+\frac{1}{2}+\cdots+\frac{1}{m}, \frac{1}{2}+\cdots+\frac{1}{m}, \cdots, \frac{1}{m}\right)
$$

Using eq. (2) and the weights in the barycenter, $B W$, it is possible to compute the utility of each alternative $a_{h}$, taking into account the criterial ranking in eq. (8). As a result, one can obtain a ranking of alternatives, Rank. The most natural way of measuring the similarity of Rank with Rank $k_{\text {Benchmark }}$ is the Kendall rank correlation coefficient (Kendall 1938).

To explain the procedure adopted, we use the following notation:

- $\quad P^{(1)}, \ldots, P^{(m !)}$ denote the different criterial rankings, where

$$
P^{(k)}=\left\{g_{(1)}^{k} \succsim g_{(2)}^{k} \succsim \cdots \succsim g_{(m)}^{k}\right\} \text { and } k=1, \ldots, m \text { ! }
$$

- $\quad B W^{(1)}, \ldots, B W^{(m !)}$ are the barycenters of the polyedra defined by the criterial rankings $P^{(1)}, \ldots, P^{(m !)}$.

- $\operatorname{Rank}^{(1)}, \ldots, \operatorname{Rank}^{(m !)}$ are the rankings of alternatives obtained by sorting the utilities of alternatives computed using eq. (2) with the barycenters $B W^{(1)}, \ldots, B W^{(m !)}$.

- $\tau^{(1)}, \ldots, \tau^{(m)}$ are the Kendall's tau values obtained by computing the correlation between the rankings of alternatives $\operatorname{Rank}^{(1)}, \ldots, \operatorname{Rank}^{(m !)}$, and $\operatorname{Rank}_{\text {Benchmark }}$.

The "best" criterial ranking, that is the best theory, will therefore be $P^{(B e s t)}$ for which the corresponding Kendall tau is the maximal value, that is:

$$
\tau^{(\text {Best })}=\max _{k=1, \ldots, m !} \tau^{(k)}
$$


It is possible that instead of a single importance ranking there is a plurality of importance rankings attaining the maximal value of the Kendall tau. In this case, especially if the importance rankings are numerous, it is reasonable to compute the frequency with which each factor is the most important, the second most important, and so on.

A didactic example showing in detail the application of the SMAA and SMAA-S methodologies can be downloaded clicking on the following link: methodological example.

\section{Variables and data}

One of the challenges in addressing entrepreneurial ecosystems is selecting the appropriate variables and data sources. Nicotra et al. (2017) have collated the most popular holistic data set, specifying the entrepreneurial ecosystem factors measured, the type of data available (typically longitudinal), and the geographic level of analysis. Referring to their study, for our purposes the data on entrepreneurial ecosystem factors are here gathered from the GEM. This is a data source of harmonized, internationally comparable data that specifically focus on entrepreneurial ecosystem factors. Each year, experts are personally interviewed or surveyed and are asked to complete the NES questionnaire. When all the data have been collected, the national files are centrally harmonized. The responses to the items follow a five-point Likert-type scale, where 1 indicates that the statement is completely false according to the expert and 5 means that the statement is completely true. The NES collects the judgments of experts evaluating specific national conditions. Also the WEF "Global Competitiveness Index" and the World Bank's "Doing Business" use similar surveys to build the indices. The main methodological difference in the case of the NES is that it focuses only on entrepreneurial ecosystem factors rather than on general economic factors. This is the reason why the GEM dataset is used in this study. Data are available from 2007 and refer to a country-level analysis in a global context.

GEM (2017) provides a complete database of entrepreneurial ecosystem indicators. The 12 factors considered by GEM are as follows:

- "Entrepreneurial Finance" [FINANCE] represents the availability of financial resources for small and medium enterprises (SMEs).

- "General Policy" [POLICY] is the extent to which public policies support entrepreneurship as a relevant economic issue.

- "Regulation" [REGUL] denotes the extent to which public policies support entrepreneurship. Taxes and regulations are either size-neutral or encourage new firms and SMEs.

- "Government Programs" [PROGRAM] concern the presence and quality of programs directly assisting SMEs at all levels of government (national, regional, municipal).

- "Primary \& Secondary Education" [EDU] denotes the extent to which training in creating and managing SMEs, i.e., entrepreneurship education, is incorporated within the education and training system at basic school (primary and secondary).

- "Post-Secondary Education" [H-EDU] is the extent to which training in creating and managing SMEs, i.e., entrepreneurship education, is incorporated within the education and training system at postsecondary levels (higher education, such as vocational education, college, business schools, etc.).

- "R\&D Transfer" [TRANSFER] represents the extent to which national research and development (R\&D) will lead to new commercial opportunities and is available to SMEs.

- "Commercial Infrastructure" [COMMER] is the presence of property rights, commercial, accounting and other legal and assessment services, and institutions that support or promote SMEs.

- "Internal Market Dynamics" [DYNAMICS] concerns the level of change in markets from year to year.

- "Internal Market Openness" [OPENNESS] is the extent to which new firms are free to enter existing markets.

- "Physical Infrastructure" [PHYSICAL] denotes the ease of access to physical resources-communication, utilities, transportation, land or space - at a price that does not discriminate against SMEs. 
- "Cultural and Social Norms" [CULTURE] represents the extent to which social and cultural norms encourage or allow actions leading to new business methods or activities that can potentially increase personal wealth and income.

To address the second objective of our analysis, we focus on entrepreneurship as the output of a successful entrepreneurial ecosystem. At the European level, in 2007, Eurostat created the Entrepreneurship Indicator Programme (EIP) in collaboration with the OECD, collecting internationally comparable statistics to "measure" entrepreneurship. From such a source it is possible to acquire data on the share of high-growth start-ups in the total number of start-ups. Deriving the average number of the available data for the last four years, we obtain the performance indicators shown in Table 1.

Table 1 Share of high-growth start-ups in the total number of start-ups (average 2012-2015) for European countries

\begin{tabular}{|lc|}
\hline European Countries & $\begin{array}{c}\text { Share of high-growth start-ups in the total } \\
\text { number of start-ups (Average 2012-2015) }\end{array}$ \\
\hline Austria & 6.67 \\
Belgium & 8.16 \\
Croatia & 8.77 \\
Denmark & 9.61 \\
Estonia & 8.20 \\
Finland & 10.64 \\
France & 8.90 \\
Germany & 11.39 \\
Hungary & 11.66 \\
Ireland & 12.17 \\
Italy & 7.20 \\
Latvia & 12.52 \\
Lithuania & 11.81 \\
Luxembourg & 9.68 \\
Netherlands & 10.02 \\
Poland & 9.17 \\
Portugal & 8.82 \\
Romania & 2.35 \\
Slovakia & 11.88 \\
Slovenia & 8.09 \\
Spain & 9.33 \\
Sweden & 12.89 \\
United Kingdom & 11.92 \\
\hline
\end{tabular}

Source: Authors' own elaboration based on Eurostat data

In justifying our choice of such a measure, first we should admit that there is no consensus on methods for measuring entrepreneurship, or the adequacy of previous and current measures (Davidsson 2004; Dennis 1997, 1999; Gartner and Shane 1995). This is because the literature on entrepreneurship has proposed a broad array of different definitions of this phenomenon (Gartner 1990; Hébert and Link 1989; Shane and Venkataraman 2000; Van Praag 1999). Entrepreneurship is a multidimensional concept that can address distinct social realities depending on the focus of the research and the theoretical perspective adopted (Bruyat and Julien 2000; Davidsson 2004; Verheul et al. 2002).

This diversity of definitions has, in turn, significant implications for the measurement of levels of entrepreneurship (see Nicotra et al. 2017). Final counts can vary depending on the view adopted by researchers in determining who is an entrepreneur, for instance, whether a firm started for self-employment is to be included in the measure of entrepreneurship, or whether the baseline for inclusion is only value creation and the 
expectation of future growth. Therefore, the lack of universally agreed indicators makes it particularly difficult to provide meaningful and reliable comparisons of the level of entrepreneurship across nations (OECD 1998).

Typically, empirical studies on entrepreneurship (Carree and Thurik 2008; Dejardin 2011; Piergiovanni et al. 2012) have considered that the entrepreneurship measure is based on net entry. Thus, the number of business owners changes over time. The variable is generally normalized with a measure for regional or country size that is commonly derived based on the number of employees, the workforce (including the unemployed), or the working age population (Audretsch and Fritsch 1994). In addition, contributions often use sector-adjusted startup rates. This is because start-up rates differ systematically across industries (Fritsch 2013).

However, considering entrepreneurship as the output of the entrepreneurial ecosystem, Isenberg (2011, p. 2) emphasizes that researchers should refer:

“...very narrowly and classically to the entrepreneur as a person who is continually pursuing economic value through growth and, as a result, is always dissatisfied with the status quo. Entrepreneurship is aspirational and risk-taking, and, I argue, intrinsically contrarian. Self-employment per se, is not entrepreneurship: self-employment-plus-aspiration, usually is; aspiration, not business ownership per se, is the continental divide between the entrepreneur and the non-entrepreneur."

Therefore, as an effect of the entrepreneurial ecosystem, we have considered a performance-based productive entrepreneurship indicator derived from the data on high-growth start-ups, i.e., emerging firms playing a certain role in contributing to economic growth and job creation (Acs and Mueller 2008; Acs et al. 2008; Birch et al. 1994; Brüderl and Preisendörfer 2000; Davidsson and Henrekson 2002; Delmar et al. 2003; Halabisky et al. 2006; Littunen and Tohmo 2003). Typically, high-growth start-ups are defined as start-ups (no more than 42 months old) the average annualized growth in number of employees of which is greater than $10 \%$ per year and with at least 10 employees at the start of the growth.

\section{Empirical analysis and results}

The analysis starts with the performance matrix (Table 2), based on the GEM (2017) data, presenting the 24 European countries in the rows and the 12 factors of the entrepreneurial ecosystems in the columns. At each intersection is the score assigned through the NES.

Applying SMAA to the performance matrix data, the rank acceptability indices, the pairwise winning indices and the central weight vectors are computed. Table 3 reports the rank acceptability indices, illustrating the frequency with which each country achieves one of the possible ranking positions from the 1 st to the 24th (i.e., the number of countries considered). It can be observed that Denmark and the Netherlands attain first position with frequencies, respectively, of $48.05 \%$ and $37.45 \%$. In contrast, Croatia, Greece, Italy, and Spain are in last position with frequencies, respectively, of $47.02 \%, 31.58 \%, 13.21 \%$, and $7.77 \%$.

Table 2 Performance matrix 


\begin{tabular}{|c|c|c|c|c|c|c|c|c|c|c|c|c|}
\hline & FINANCE & POLICY & \begin{tabular}{|l} 
REGUL \\
\end{tabular} & PROGRAM & EDU & H-EDU & \begin{tabular}{|l|} 
TRANSFER \\
\end{tabular} & COMMER & DYNAMICS & OPENESS & \begin{tabular}{|l} 
PHYSICAL \\
\end{tabular} & CULTURE \\
\hline \begin{tabular}{|l|} 
Austria \\
\end{tabular} & 2.51 & 2.46 & 2.6 & 3.58 & 1.66 & 3.02 & 2.82 & 3.4 & 2.49 & 3.33 & 4.12 & 2.46 \\
\hline Belgium & 3.38 & 2.62 & 1.98 & 2.71 & 1.95 & 2.75 & 2.99 & 3.74 & 2.5 & 3.19 & 3.79 & 2.15 \\
\hline \begin{tabular}{|l} 
Croatia \\
\end{tabular} & 2.32 & 2.15 & 1.55 & 2.27 & 1.68 & 2.35 & 2.04 & 2.9 & 3.37 & 2.08 & 3.67 & 2.02 \\
\hline \begin{tabular}{|l|} 
Denmark \\
\end{tabular} & 2.73 & 3.33 & 3.31 & 3.43 & 3.1 & 3.43 & 2.77 & 3.56 & 2.43 & 3.44 & 4.49 & 2.82 \\
\hline \begin{tabular}{|l} 
Estonia \\
\end{tabular} & 2.86 & 2.43 & 3.58 & 3.39 & 2.63 & 2.99 & 2.92 & 3.21 & 3.39 & 3.12 & 4.39 & 3.39 \\
\hline Finland & 2.82 & 3.17 & 2.95 & 2.77 & 2.28 & 2.7 & 2.61 & 3.2 & 3.23 & 2.72 & 4.25 & 2.76 \\
\hline France & 2.77 & 2.99 & 2.96 & 3.17 & 1.75 & 2.92 & 2.73 & 3.06 & 3.02 & 2.34 & 4.04 & 2.14 \\
\hline \begin{tabular}{|l|} 
Germany \\
\end{tabular} & 2.84 & 2.93 & 2.87 & 3.46 & 2.13 & 2.81 & 2.75 & 3.34 & 2.84 & 2.81 & 3.82 & 2.65 \\
\hline Greece & 2.11 & \begin{tabular}{|l|l|}
2.07 \\
\end{tabular} & 1.74 & 1.95 & 1.5 & 2.31 & 2.26 & 3.05 & 3.42 & 2.12 & 3.53 & 2.47 \\
\hline Hungary & 2.63 & 2.43 & 1.93 & 2.41 & 1.68 & 2.82 & 2.41 & 3.29 & 3.13 & 2.62 & 3.94 & 2.32 \\
\hline Ireland & 2.87 & 3.24 & 2.64 & 3.26 & 2.09 & 2.95 & 2.82 & 3.29 & 2.59 & 3.13 & 3.71 & 2.95 \\
\hline Italy & 2.55 & 2.4 & 1.5 & 2.08 & 1.68 & 2.33 & 2.18 & 2.83 & 3.5 & 2.61 & 2.92 & 2.22 \\
\hline \begin{tabular}{|l|l|} 
Latvia \\
\end{tabular} & 2.55 & 2.6 & 2.5 & 2.75 & 2.51 & 3.17 & 2.33 & 3.74 & 2.27 & 2.78 & 4 & 2.85 \\
\hline \begin{tabular}{|l|} 
Lithuania \\
\end{tabular} & 3.19 & 2.39 & 2.46 & 2.72 & \begin{tabular}{|l|l|}
2.37 \\
\end{tabular} & \begin{tabular}{|l|}
3.07 \\
\end{tabular} & 2.61 & 3.9 & 3.38 & 2.66 & 4.19 & 3.09 \\
\hline Luxembourg & 2.76 & 3.41 & 3.22 & 3.47 & 2.13 & 2.9 & 2.98 & 3.5 & 2.76 & 3.05 & 4.04 & 2.56 \\
\hline Netherlands & 2.81 & 2.59 & 3.13 & 3.15 & 2.85 & 3.17 & 2.88 & 3.68 & 2.85 & 3.4 & 4.82 & 3.58 \\
\hline Poland & 2.77 & 3.07 & 2.16 & 2.77 & 1.75 & \begin{tabular}{|l|}
2.54 \\
\end{tabular} & 2.44 & 2.77 & 4.04 & 2.75 & 3.79 & 2.96 \\
\hline \begin{tabular}{|l|} 
Portugal \\
\end{tabular} & 2.73 & 2.57 & 2.01 & 3 & 2.04 & \begin{tabular}{|l|l|}
3.04 \\
\end{tabular} & 2.76 & 3.34 & 2.4 & 2.75 & 4.43 & 2.55 \\
\hline Romania & 2.43 & 2.53 & 2.24 & 2.51 & 2.34 & 2.68 & 2.59 & 3.09 & 3.14 & 2.86 & 2.89 & 2.61 \\
\hline Slovakia & 2.73 & 2.28 & 2.16 & 2.26 & 2.21 & 2.98 & 2.13 & 3.07 & 2.63 & 2.84 & 3.94 & 2.4 \\
\hline \begin{tabular}{|l|} 
Slovenia \\
\end{tabular} & 2.33 & 2.13 & 1.92 & 2.43 & 1.77 & 2.34 & 2.29 & 2.71 & 3.04 & 2.56 & 3.56 & 2.06 \\
\hline Spain & 2.14 & 2.5 & 2.4 & 2.88 & 1.84 & 2.61 & 2.45 & 3.03 & 2.87 & 2.47 & 3.64 & 2.64 \\
\hline Sweden & 2.63 & 2.74 & 2.53 & 3 & 2.55 & 2.75 & 2.65 & 3.28 & 3.13 & 2.8 & 4.25 & $\begin{array}{ll}3.07 \\
\end{array}$ \\
\hline United Kingdom & 2.77 & 2.9 & 2.33 & 2.62 & 2.44 & 3.02 & 2.2 & 2.95 & 3.28 & 2.73 & 3.54 & 2.83 \\
\hline
\end{tabular}

Source: GEM (2017)

Table 3 Rank acceptability index

\begin{tabular}{|c|c|c|c|c|c|c|c|c|c|c|c|c|c|c|c|c|c|c|c|c|c|c|c|c|}
\hline & $\# 1$ & $\# 2$ & $\# 3$ & $\# 4$ & $\# 5$ & $\# 6$ & $\# 7$ & $\# 8$ & $\# 9$ & $\# 10$ & $\# 11$ & $\# 12$ & $\# 13$ & $\# 14$ & $\# 15$ & $\# 16$ & $\# 17$ & $\# 18$ & $\# 19$ & $\# 20$ & $\# 21$ & $\# 22$ & $\# 23$ & $\# 24$ \\
\hline Austria & 0.00 & 0.01 & 0.11 & 0.93 & 5.27 & 6.88 & 7.97 & 7.89 & 8.23 & 8.90 & 10.91 & 11.14 & 10.53 & 7.90 & 5.81 & 4.49 & 1.82 & 0.79 & 0.24 & 0.09 & 0.04 & 0.02 & 0.01 & 0.01 \\
\hline Belgium & .40 & 0.40 & 0.92 & 2.21 & 4.97 & 7.15 & 6.64 & 5.99 & 6.01 & .87 & 8.10 & 9.40 & 10.06 & 9.38 & 8.19 & 7.82 & .64 & 1.64 & 0.72 & 0.30 & 0.09 & 0.05 & 0.03 & 0.01 \\
\hline Croatia & 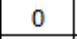 & 0 & 0 & 0 & 0 & 0 & 0 & 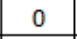 & 0 & 0.00 & 0.00 & 0.00 & 0.00 & 0.01 & 0.01 & 0.03 & 0.06 & 0.07 & 0.10 & 0.41 & 2.32 & 13.59 & 36.39 & 47.02 \\
\hline Denmark & 8.05 & 25.41 & 18.61 & 5.08 & 1.45 & 0.57 & 0.37 & 0.23 & 0.10 & 0.05 & 0.03 & 0.01 & 0.01 & 0.00 & 0.00 & 0.01 & 0.00 & 0.00 & 0.00 & 0.00 & 0 & 0 & 0 & 0 \\
\hline Esto & 1.13 & 17.67 & 44.24 & 14.85 & 6.25 & 2.99 & 1.48 & 0.64 & 0.36 & 0.20 & 0.13 & 0.05 & 0.02 & 0.01 & 0.00 & 0.00 & 0 & 0 & 0 & 0 & 0 & 0 & 0 & 0 \\
\hline Finla & 0 & 0.01 & 0.29 & 1.36 & 7.42 & 13.26 & 13.56 & 13.38 & 13.72 & 11.97 & 9.87 & 7.48 & 5.89 & 1.46 & 0.28 & 0.05 & 0.00 & 0 & 0 & 0 & 0 & 0 & 0 & 0 \\
\hline Fran & 0 & 0 & 0 & 0.00 & 0.05 & 0.39 & 1.13 & 3.59 & 4.52 & 6.96 & 9.12 & 12.07 & 14.01 & 17.71 & 10.77 & 8.95 & 5.58 & 3.22 & 1.45 & 0.45 & 0.03 & 0.00 & 0 & 0 \\
\hline Ger & 0 & 0.00 & 0.01 & 0.16 & 3.38 & 10.35 & 15.95 & 19.83 & 20.10 & 15.58 & 9.49 & 3.91 & 1.10 & 0.12 & 0.02 & 0.00 & 0 & 0 & 0 & 0 & 0 & 0 & 0 & 0 \\
\hline Greece & 0 & 0 & 0 & 0 & 0 & 0 & 0.00 & 0.00 & 0.00 & 0.00 & 0.00 & 0.00 & 0.01 & 0.02 & 0.03 & 0.07 & 0.08 & 0.14 & 0.20 & 0.85 & 14.57 & 19.06 & 33.37 & 31.58 \\
\hline Hun & 0 & 0 & 0 & 0 & 0 & 0 & 0 & 0.00 & 0.00 & .01 & 0.02 & 0.08 & .19 & 0.93 & 2.97 & 5.69 & 17.42 & 27.77 & 30.54 & 14.39 & 0.00 & 0 & 0 & 0 \\
\hline Irelan & 0.00 & 0.01 & 1.96 & 5.86 & 22.64 & 21.44 & 17.56 & 11.28 & 7.90 & 5.28 & 3.31 & 1.80 & 0.68 & 0.17 & 0.06 & 0.03 & 0.02 & 0.00 & 0.00 & 0.00 & 0.00 & 0 & 0 & 0 \\
\hline Italy & 0 & 0 & 0 & 0 & 0.00 & 0.00 & 0.00 & 0.01 & 0.01 & 0.01 & 0.01 & 0.02 & 0.03 & 0.08 & 0.13 & 0.17 & 0.23 & 0.31 & 0.56 & 3.79 & 34.11 & 32.08 & 15.26 & 13.21 \\
\hline Latvia & 0 & 0 & 0.02 & 0.50 & 2.08 & 3.93 & 4.46 & 4.99 & 5.97 & 8.72 & 9.60 & 11.75 & 11.74 & 13.40 & 9.73 & 7.71 & 2.76 & 1.33 & 0.61 & 0.27 & 0.13 & 0.11 & 0.09 & 0.11 \\
\hline Lithuania & 1.49 & 2.53 & 8.57 & 22.17 & 17.32 & 10.92 & 8.62 & 8.08 & 7.11 & 4.85 & 3.91 & 2.38 & 1.24 & 0.48 & 0.21 & 0.13 & 0.01 & 0.00 & 0 & 0 & 0 & 0 & 0 & 0 \\
\hline Luxembourg & 1.13 & 8.86 & 12.44 & 40.25 & 19.83 & 9.11 & 4.63 & 2.22 & 1.05 & 0.35 & 0.10 & 0.02 & 0.00 & 0.00 & 0.00 & 0 & 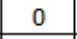 & 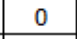 & 0 & 0 & 0 & 0 & 0 & 0 \\
\hline Netherla & 37.45 & 44.60 & 12.17 & 4.16 & 0.91 & 0.43 & 0.16 & 0.07 & 0.04 & 0.01 & 0.00 & 0.00 & 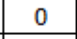 & 0 & 0 & 0 & 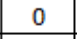 & 0 & 0 & 0 & 0 & 0 & 0 & 0 \\
\hline Poland & 0.37 & 0.51 & 0.64 & 1.16 & 1.52 & 1.76 & 2.15 & 2.73 & 3.18 & 4.75 & 5.73 & 7.20 & 7.33 & 11.48 & 15.88 & 16.11 & 8.06 & .45 & 2.82 & 1.19 & 0.01 & 0.00 & 0 & 0 \\
\hline Portugal & 0 & 0 & 0 & 0.02 & 0.15 & 0.46 & 0.89 & 1.94 & 3.26 & 5.45 & 9.26 & 15.57 & 21.23 & 16.83 & 12.33 & 7.87 & 2.95 & 0.98 & 0.37 & 0.19 & 0.12 & 0.09 & 0.04 & 0.02 \\
\hline Romania & 0 & 0 & 0 & 0 & 0 & 0 & 0 & 0.01 & 0.02 & 0.07 & 0.16 & 0.96 & 2.22 & 4.50 & 8.88 & 13.45 & 27.63 & 16.69 & 14.97 & 9.75 & 0.27 & 0.21 & 0.20 & 0.00 \\
\hline Slovakia & 0 & 0 & 0 & 0 & 0 & 0 & 0 & 0.00 & 0.00 & 0.00 & 0.01 & 0.03 & 0.17 & 0.80 & 2.88 & 7.95 & 16.14 & 20.39 & 20.16 & 28.38 & 1.65 & 0.69 & 0.49 & 0.26 \\
\hline Slovenia & 0 & 0 & 0 & 0 & 0 & 0 & 0 & 0 & 0 & 0 & 0 & 0 & 0 & 0 & 0 & 0.00 & 0.00 & 0.00 & 0.02 & 0.58 & 43.87 & 33.78 & 13.98 & 7.77 \\
\hline Spain & 0 & 0 & 0 & 0 & 0 & 0 & 0 & 0 & 0 & 0 & 0 & 0 & 0.01 & 0.08 & 0.64 & 2.58 & 8.81 & 18.97 & 26.32 & 39.35 & 2.80 & 0.31 & 0.13 & 0.02 \\
\hline Sweden & 0 & 0 & 0.00 & 1.28 & 6.62 & 9.91 & 13.57 & 15.41 & 15.57 & 15.72 & 11.76 & 6.70 & 2.43 & 0.76 & 0.25 & 0.02 & 0.00 & 0 & 0 & 0 & 0 & 0 & 0 & 0 \\
\hline United Kingdom & 0 & 0 & 0 & 0.01 & 0.15 & 0.45 & 0.87 & 1.72 & 2.86 & 4.26 & 8.47 & 9.43 & 11.09 & 13.90 & 20.93 & 16.89 & 5.78 & 2.26 & 0.92 & 0.01 & 0 & 0 & 0 & 0 \\
\hline
\end{tabular}

The results are enriched by the figures given in Tables 4 and 5. Table 4 shows, for each country, the best and the worst positions attainable based on the results of the rank acceptability indices. As already noted, Denmark attains first position with a frequency of $48.05 \%$, together with the Netherlands with a frequency of $37.45 \%$. As far as the worst position is concerned, the frequency for 20 countries is very close to zero. Again, only Croatia, Greece, Italy, and Spain can be in 24th position with a certain frequency. Table 5 shows the most frequent position, i.e., the mode, for each country. The most frequent position for Denmark is first, for the Netherlands it is second, for Estonia it is third (44.24\%), for Lithuania and Luxembourg it is fourth $(22.17 \%$ and $40.25 \%$, respectively), for Germany and Finland it is ninth $(20.10 \%$ and $13.72 \%$, respectively), and so on. The table also shows, for each country, the second and the third most frequent positions. The pairwise winning indices are shown in Table 6 . These refer to the frequency with which a country is preferred over another country. Germany, 
for example, is preferred over Italy with a frequency of $99.97 \%$, and Italy is preferred over Greece with a frequency of $69.11 \%$. 
Table 4 Best-worst positions

\begin{tabular}{|c|c|c|c|c|}
\hline & Best Position & Rai Best Position (\%) & Worst Position & Rai Worst Position (\%) \\
\hline Austria & 1 & 0.00 & 24 & 0.01 \\
\hline Belgium & 1 & 0.40 & 24 & 0.01 \\
\hline Croatia & 10 & 0.00 & 24 & 47.02 \\
\hline Denmark & 1 & 48.05 & 20 & 0.00 \\
\hline Estonia & 1 & 11.13 & 16 & 0.00 \\
\hline Finland & 2 & 0.01 & 17 & 0.00 \\
\hline France & 4 & 0.00 & 22 & 0.00 \\
\hline Germany & 2 & 0.00 & 16 & 0.00 \\
\hline Greece & 7 & 0.00 & 24 & 31.58 \\
\hline Hungary & 8 & 0.00 & 21 & 0.00 \\
\hline Ireland & 1 & 0.00 & 21 & 0.00 \\
\hline Italy & 5 & 0.00 & 24 & 13.21 \\
\hline Latvia & 3 & 0.02 & 24 & 0.11 \\
\hline Lithuania & 1 & 1.49 & 18 & 0.00 \\
\hline Luxembourg & 1 & 1.13 & 15 & 0.00 \\
\hline Netherlands & 1 & 37.45 & 12 & 0.00 \\
\hline Poland & 1 & 0.37 & 22 & 0.00 \\
\hline Portugal & 4 & 0.02 & 24 & 0.02 \\
\hline Romania & 8 & 0.01 & 24 & 0.00 \\
\hline Slovakia & 8 & 0.00 & 24 & 0.26 \\
\hline Slovenia & 16 & 0.00 & 24 & 7.77 \\
\hline Spain & 13 & 0.01 & 24 & 0.02 \\
\hline Sweden & 3 & 0.00 & 17 & 0.00 \\
\hline United Kingdom & 4 & 0.01 & 20 & 0.01 \\
\hline
\end{tabular}

Table 5 Most frequent positions

\begin{tabular}{|c|c|c|c|c|c|c|}
\hline & First Most Frequent Position & RAI MF1 (\%) & Second Most Frequent & RAI MF2 (\%) & Third Most Frequent & RAI MF3 (\%) \\
\hline Austria & 12 & 11.14 & 11 & 10.91 & 13 & 10.53 \\
\hline Belgium & 13 & 10.06 & 12 & 9.40 & 14 & 9.38 \\
\hline Croatia & 24 & 47.02 & 23 & 36.39 & 22 & 13.59 \\
\hline Denmark & 1 & 48.05 & 2 & 25.41 & 3 & 18.61 \\
\hline Estonia & 3 & 44.24 & 2 & 17.67 & 4 & 14.85 \\
\hline Finland & 9 & 13.72 & 7 & 13.56 & 8 & 13.38 \\
\hline France & 14 & 17.71 & 13 & 14.01 & 12 & 12.07 \\
\hline Germany & 9 & 20.10 & 8 & 19.83 & 7 & 15.95 \\
\hline Greece & 23 & 33.37 & 24 & 31.58 & 22 & 19.06 \\
\hline Hungary & 19 & 30.54 & 18 & 27.77 & 17 & 17.42 \\
\hline Ireland & 5 & 22.64 & 6 & 21.44 & 7 & 17.56 \\
\hline Italy & 21 & 34.11 & 22 & 32.08 & 23 & 15.26 \\
\hline Latvia & 14 & 13.40 & 12 & 11.75 & 13 & 11.74 \\
\hline Lithuania & 4 & 22.17 & 5 & 17.32 & 6 & 10.92 \\
\hline Luxembourg & 4 & 40.25 & 5 & 19.83 & 3 & 12.44 \\
\hline Netherlands & 2 & 44.60 & 1 & 37.45 & 3 & 12.17 \\
\hline Poland & 16 & 16.11 & 15 & 15.88 & 14 & 11.48 \\
\hline Portugal & 13 & 21.23 & 14 & 16.83 & 12 & 15.57 \\
\hline Romania & 17 & 27.63 & 18 & 16.69 & 19 & 14.97 \\
\hline Slovakia & 20 & 28.38 & 18 & 20.39 & 19 & 20.16 \\
\hline Slovenia & 21 & 43.87 & 22 & 33.78 & 23 & 13.98 \\
\hline Spain & 20 & 39.35 & 19 & 26.32 & 18 & 18.97 \\
\hline Sweden & 10 & 15.72 & 9 & 15.57 & 8 & 15.41 \\
\hline United Kingdom & 15 & 20.93 & 16 & 16.89 & 14 & 13.90 \\
\hline
\end{tabular}


Table 6 Pairwise winning indices

\begin{tabular}{|c|c|c|c|c|c|c|c|c|c|c|c|c|c|c|c|c|c|c|c|c|c|c|c|c|}
\hline & Austria & Belgium & Croatia & Denmark & Estonia & Finland & France & Germany & Greece & Hungary & Ireland & Italy & Latvia & Lithuania & Luxembourg & Netherlands & Poland & Portugal & | Romania & Slovakia & Slovenia & Spain & Sweden & United Kingdon \\
\hline Austria & 0 & 55.27 & 99.85 & 0.00 & 0.46 & 36.07 & 71.63 & 26.94 & 99.78 & 98.49 & 14.50 & \begin{tabular}{|l|}
99.53 \\
\end{tabular} & \begin{tabular}{|l|}
61.80 \\
\end{tabular} & 19.62 & 1.20 & 0.08 & 71.60 & 76.16 & 94.17 & 98.16 & 99.97 & 99.70 & 35.47 & 72.29 \\
\hline Belgium & 44.73 & 0 & 99.83 & 1.43 & 4.34 & 33.79 & 64.13 & 29.40 & 99.69 & 97.94 & \begin{tabular}{|l|l|}
17.48 \\
\end{tabular} & \begin{tabular}{|l|}
99.58 \\
\end{tabular} & 55.58 & 13.86 & 5.66 & 0.84 & 67.98 & 67.43 & 92.74 & 97.51 & 99.95 & 96.98 & 33.57 & 67.70 \\
\hline Croatia & 0.15 & 0.17 & 0.00 & 0.01 & 0 & 0 & 0.00 & 0.00 & 38.84 & 0.00 & 0.03 & 19.25 & 0.37 & 0 & 0.00 & 0 & 0.00 & 0.26 & 0.51 & 0.82 & 13.02 & 0.47 & 0 & 0.00 \\
\hline Denmark & 100.00 & $\begin{array}{ll}98.57 \\
\end{array}$ & 99.99 & 0 & 73.32 & 98.97 & 99.90 & 99.85 & 99.98 & $\begin{array}{ll}99.98 \\
\end{array}$ & 99.90 & \begin{tabular}{|l|}
99.97 \\
\end{tabular} & 100.00 & 91.98 & 96.39 & 51.89 & 97.80 & 100.00 & 99.97 & 100.00 & 100.00 & 100.00 & 99.27 & 99.74 \\
\hline Estonia & 99.54 & 95.66 & 100.00 & 26.68 & 0 & 96.90 & 99.50 & 98.28 & 100.00 & 100.00 & 92.58 & 100.00 & \begin{tabular}{|l|l|}
98.74 \\
\end{tabular} & 88.67 & 77.07 & 17.21 & 98.87 & 99.98 & 100.00 & 100.00 & 100.00 & 100.00 & 99.73 & 99.78 \\
\hline Finland & 63.93 & 66.21 & 100.00 & 1.03 & 3.10 & 0 & 93.00 & 49.12 & 100.00 & 99.99 & \begin{tabular}{|l|}
26.52 \\
\end{tabular} & 100.00 & \begin{tabular}{|l|}
77.12 \\
\end{tabular} & 23.14 & 5.14 & 1.15 & 92.62 & 85.53 & 99.99 & 99.85 & 100.00 & 100.00 & 48.03 & 96.05 \\
\hline France & 28.37 & 35.87 & 100.00 & 0.10 & 0.50 & 7.00 & 0 & 2.81 & 99.96 & 96.80 & 3.55 & \begin{tabular}{|l|}
99.87 \\
\end{tabular} & 43.05 & 8.06 & 0.03 & 0.13 & 59.40 & $\begin{array}{lll}44.74 \\
\end{array}$ & 86.76 & 92.45 & 100.00 & 98.62 & 13.65 & 58.73 \\
\hline Germany & 73.06 & 70.60 & 100.00 & 0.15 & 1.72 & 50.88 & 97.19 & 0 & 99.99 & 99.97 & \begin{tabular}{|l|}
19.79 \\
\end{tabular} & \begin{tabular}{|l|}
99.97 \\
\end{tabular} & \begin{tabular}{|l|}
79.42 \\
\end{tabular} & 26.19 & 0.12 & 0.41 & 87.59 & 91.92 & 99.87 & 99.96 & 100.00 & 100.00 & 54.67 & 92.35 \\
\hline Greece & 0.22 & 0.31 & 61.16 & 0.02 & 0 & 0 & 0.04 & 0.01 & 0 & 0.03 & 0.05 & \begin{tabular}{|l|}
30.89 \\
\end{tabular} & 0.52 & 0 & 0.01 & 0.00 & 0.01 & 0.40 & 0.38 & 1.77 & 25.97 & 0.57 & 0 & 0.00 \\
\hline Hungary & 1.51 & 2.06 & 100.00 & 0.02 & 0 & 0.01 & 3.20 & 0.03 & 99.97 & 0 & 0.19 & 99.80 & 3.66 & 0 & 0.01 & 0 & 8.36 & 2.56 & 34.13 & 55.52 & 100.00 & 66.85 & 0.00 & 5.91 \\
\hline Ireland & 85.50 & 82.52 & 99.97 & 0.10 & 7.42 & 73.48 & 96.45 & 80.21 & 99.95 & 99.81 & 0 & \begin{tabular}{|l|}
99.92 \\
\end{tabular} & \begin{tabular}{|l|}
88.76 \\
\end{tabular} & 41.11 & 6.74 & 2.23 & 91.41 & 96.19 & 99.73 & 99.99 & 100.00 & 100.00 & 73.01 & 96.14 \\
\hline Italy & 0.47 & 0.42 & 80.75 & 0.03 & 0 & 0 & 0.13 & 0.03 & 69.11 & 0.20 & 0.08 & 0.00 & 1.00 & 0 & 0.02 & 0.00 & 0 & 0.80 & 0.10 & 2.98 & 47.38 & 3.97 & 0.00 & 0.00 \\
\hline Latvia & 38.20 & \begin{tabular}{ll|}
44.42 \\
\end{tabular} & 99.63 & 0.00 & 1.26 & 22.88 & 56.95 & 20.58 & 99.48 & 96.34 & \begin{tabular}{|l|}
11.24 \\
\end{tabular} & \begin{tabular}{|l|}
99.00 \\
\end{tabular} & 0 & 2.51 & 3.47 & 0 & 63.11 & 60.46 & 92.21 & 99.50 & 99.79 & 98.61 & 17.76 & 70.88 \\
\hline Lithuania & 80.38 & 86.14 & 100.00 & 8.02 & 11.33 & 76.86 & 91.94 & 73.81 & 100.00 & 100.00 & \begin{tabular}{|l|}
58.89 \\
\end{tabular} & 100.00 & \begin{tabular}{|l|}
97.49 \\
\end{tabular} & 0 & 35.47 & 2.73 & 93.02 & 97.06 & 99.98 & 100.00 & 100.00 & 100.00 & 79.07 & 97.76 \\
\hline Luxembourg & 98.81 & 94.34 & 100.00 & 3.61 & 22.93 & 94.86 & 99.97 & 99.88 & 99.99 & 99.99 & \begin{tabular}{|l|}
93.26 \\
\end{tabular} & \begin{tabular}{|l|}
99.98 \\
\end{tabular} & \begin{tabular}{|l|}
96.53 \\
\end{tabular} & 64.53 & 0 & 11.02 & 95.61 & 99.72 & 99.97 & 100.00 & 100.00 & 100.00 & 90.93 & 98.48 \\
\hline Netherlands & 99.92 & 99.16 & 100.00 & 48.11 & 82.79 & 98.85 & 99.87 & 99.59 & 100.00 & 100.00 & \begin{tabular}{|l|l|}
97.77 \\
\end{tabular} & 100.00 & 100.00 & 97.27 & 88.98 & 0 & 98.65 & 100.00 & 100.00 & 100.00 & 100.00 & 100.00 & 99.98 & 99.94 \\
\hline Poland & 28.40 & 32.02 & 100.00 & 2.20 & 1.13 & 7.38 & 40.60 & 12.41 & 99.99 & \begin{tabular}{|l|}
91.64 \\
\end{tabular} & 8.59 & 100.00 & \begin{tabular}{|l|}
36.89 \\
\end{tabular} & 6.98 & 4.39 & 1.35 & 0 & \begin{tabular}{|l|l|}
38.84 \\
\end{tabular} & 85.04 & 87.62 & 100.00 & 97.43 & 10.57 & 53.54 \\
\hline Portugal & 23.84 & \begin{tabular}{|l|}
32.57 \\
\end{tabular} & \begin{tabular}{|l|}
99.74 \\
\end{tabular} & 0 & 0.02 & 14.47 & \begin{tabular}{|l|}
55.26 \\
\end{tabular} & 8.08 & 99.60 & \begin{tabular}{|l|}
97.44 \\
\end{tabular} & 3.81 & \begin{tabular}{|l|}
99.20 \\
\end{tabular} & \begin{tabular}{|l|}
39.54 \\
\end{tabular} & 2.94 & 0.28 & 0 & 61.16 & 0 & 90.37 & \begin{tabular}{|l}
99.25 \\
\end{tabular} & 99.90 & 98.79 & 9.37 & 59.79 \\
\hline Romania & 5.83 & 7.26 & \begin{tabular}{|l|}
99.49 \\
\end{tabular} & 0.03 & 0 & 0.01 & 13.24 & 0.13 & 99.62 & 65.87 & 0.27 & \begin{tabular}{|l|}
99.90 \\
\end{tabular} & 7.79 & 0.02 & 0.03 & 0 & 14.96 & 9.63 & 0 & 67.73 & 99.51 & 80.82 & 0 & 8.65 \\
\hline Slovakia & 1.84 & 2.49 & \begin{tabular}{|l|}
99.18 \\
\end{tabular} & 0 & 0 & 0.15 & 7.55 & 0.04 & 98.23 & \begin{tabular}{|l|l|}
44.48 \\
\end{tabular} & 0.01 & \begin{tabular}{|l|}
97.02 \\
\end{tabular} & 0.50 & 0.00 & 0.00 & 0 & \begin{tabular}{|l|}
12.38 \\
\end{tabular} & 0.75 & 32.27 & 0 & 99.17 & 58.63 & 0.06 & 1.61 \\
\hline Slovenia & 0.03 & 0.05 & 86.98 & 0.00 & 0 & 0 & \begin{tabular}{ll|}
0.00 \\
\end{tabular} & 0 & $\begin{array}{l}74.03 \\
\end{array}$ & 0.00 & 0.00 & 52.62 & 0.21 & 0 & 0 & 0 & 0 & 0.10 & 0.49 & 0.83 & 0 & 0.25 & 0 & 0.00 \\
\hline Spain & 0.30 & 3.02 & \begin{tabular}{|l|}
99.53 \\
\end{tabular} & 0.00 & 0 & 0 & 1.38 & 0 & 99.43 & 33.15 & 0.00 & \begin{tabular}{|l|}
96.03 \\
\end{tabular} & \begin{tabular}{ll|}
1.39 \\
\end{tabular} & 0.00 & 0 & 0 & 2.57 & 1.21 & 19.18 & 41.37 & 99.75 & 0 & 0 & 2.47 \\
\hline Sweden & 64.53 & 66.43 & 100.00 & 0.73 & 0.27 & 51.97 & 86.35 & 45.33 & 100.00 & 100.00 & 26.99 & 100.00 & \begin{tabular}{|l|}
82.24 \\
\end{tabular} & 20.93 & 9.07 & 0.02 & 89.43 & 90.63 & 100.00 & 99.94 & 100.00 & 100.00 & 0 & 95.83 \\
\hline \begin{tabular}{l|} 
United Kingdom \\
\end{tabular} & 27.71 & 32.30 & 100.00 & 0.26 & 0.22 & 3.95 & 41.27 & 7.65 & 100.00 & 94.09 & 3.86 & 100.00 & 29.12 & 2.24 & 1.52 & 0.06 & 46.46 & 40.21 & 91.35 & 98.39 & 100.00 & 97.53 & 4.17 & 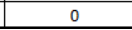 \\
\hline
\end{tabular}

All this information conveys several valuable results. In what follows, we address some of the most interesting, particularly with respect to the two best performing countries, namely Denmark and the Netherlands.

Table 4 shows that nine countries (Austria, Belgium, Denmark, Estonia, Ireland, Lithuania, Luxembourg, the Netherlands, and Poland) can attain the optimal position. This means that there is at least one weight vector for which these countries can attain first position in the ranking. In terms of DEA (Charnes et al. 1987), the methodology most commonly adopted for this type of analysis, these would be the only efficient countries. However, we observe that the information supplied by SMAA is much more powerful because it not only indicates that these countries are efficient, but also gives a measure of their efficiency in terms of the probability of occupying first position (see also the comments in Greco et al. 2017). Thus, while for DEA all the nine countries present the same maximal level of efficiency, without any further discrimination between them, SMAA suggests that Denmark and the Netherlands are more efficient than the other seven countries because they have a greater probability of attaining first position in the ranking. This means that there is a large share of weight vectors for which these two countries can occupy the first ranking position (48.05\% for Denmark and $37.45 \%$ for the Netherlands).

It is also interesting to undertake a pairwise comparison of these two countries. This can be done using the data reported in Table 6 . Here, we observe that the advantage of Denmark over the Netherlands is quite small as Denmark is preferred to the Netherlands for $51.89 \%$ of the weight vectors, while for the remaining $48.11 \%$ there is an inverse preference. The reason Denmark can in any case be considered preferred over the Netherlands goes further than the simple analysis of the frequency of preference for one country over another. Indeed, looking at Table 3, one can observe that there is a greater probability of the Netherlands being the second most preferred country $(44.60 \%)$ than Denmark $(25.41 \%)$. Taking into account the probability of being the most preferred country and the probability of being the second most preferred country, one can compute the probability of being at least the second most preferred country as $73.46 \%$ for Denmark and $82.05 \%$ for the Netherlands (Angilella et al. 2016). This can be interpreted as indicating that in terms of the first two positions, the Netherlands exhibits more stable performance overall than Denmark. This greater stability in the performance of the Netherlands with respect to that of Denmark is confirmed by the extreme ranking positions taken by the two countries, as shown in Table 4. Indeed, while the ranking position of Denmark can range from the 1st to the 20th, the position of the Netherlands can vary only between the 1 st and the 12th. Similar conclusions can be drawn more synthetically from Table 5, which presents the three most frequent ranking positions for each country. From this, we can see that the three most frequent ranking positions are first, second, and third for Denmark, with probabilities of $48.05 \%, 25.41 \%$, and $18.61 \%$, respectively, and those for the Netherlands are second, first, and third, with probabilities of $44.60 \%, 37.45 \%$, and $12.17 \%$, respectively.

Similar analyses can be undertaken with respect to the other countries. Further information is supplied by the SMAA methodology, as shown in the following section.

Table 7 reports for Italy, the average preferences giving a certain position (central weight vector for all positions). Such analysis provides information on the main aspects permitting a certain country to attain a certain 
position. In this way, the country can gain an understanding of its strengths and weaknesses. Indeed, $w^{c}\left(a_{k}, r\right)$, the central weight vector related to the ranking position $r$, represents the importance to be attributed to the different factors that influence attaining ranking position $r$. In this regard, we note the following:

- Factors with high values for $w^{c}\left(a_{k}, r\right)$ related to the best ranking positions and small values for $w^{c}\left(a_{k}, r\right)$ related to the worst ranking positions represent strengths for the country considered.

- Factors with small values for $w^{c}\left(a_{k}, r\right)$ related to the best ranking position and high values for $w^{c}\left(a_{k}, r\right)$ related to the worst ranking position represent weaknesses for the country considered.

The information on strengths and weaknesses should help policymakers define appropriate strategies to improve a country's performance. Indeed, designing a strategy that enhances and sustains strengths and protects from the negative effects of weaknesses will put the country in a position that enables it to attain better performance with respect to other countries. This is in agreement with Porter's (1990) approach to competitive advantage, interpreted as the availability of certain factors.

Focusing on the implications for Italy, Table 7 indicates that the country cannot attain the first four positions. However, Italy could gain a more optimal position (fourth) if "Internal Market Dynamics" had more than half of the weight $(68.35 \%)$. Therefore, this factor could be considered a potential strength of the entrepreneurial ecosystem in Italy. In contrast, looking at the last row, we can observe that physical infrastructure is the weakest factor for Italy. Indeed, if a major weight is assigned to this factor, Italy loses ground and goes down to the lowest positions.

Table 7 Central weight vector (for all positions): Italy

\begin{tabular}{|c|c|c|c|c|c|c|c|c|c|c|c|c|}
\hline & FINANCE & POLICY & REGUL & PROGRAM & EDU & H-EDU & TRANSFER & COMMER & DYNAMICS & OPENESS & PHYSICAL & CULTURE \\
\hline$\# 1$ & 0 & 0 & 0 & 0 & 0 & 0 & 0 & 0 & 0 & 0 & 0 & 0 \\
\hline$\# 2$ & 0 & 0 & 0 & 0 & 0 & 0 & 0 & 0 & 0 & 0 & 0 & 0 \\
\hline$\# 3$ & 0 & 0 & 0 & 0 & 0 & 0 & 0 & 0 & 0 & 0 & 0 & 0 \\
\hline$\# 4$ & 0 & 0 & 0 & 0 & 0 & 0 & 0 & 0 & 0 & 0 & 0 & 0 \\
\hline$\# 5$ & 5.744 & 1.179 & 0.913 & 0.301 & 2.251 & 1.220 & 5.459 & 2.184 & 68.353 & 4.068 & 5.144 & 3.183 \\
\hline$\# 6$ & 7.247 & 5.051 & 2.980 & 2.275 & 1.550 & 2.391 & 1.518 & 2.044 & 63.963 & 5.646 & 1.959 & 3.375 \\
\hline$\# 7$ & 3.091 & 7.637 & 2.828 & 2.247 & 3.768 & 2.237 & 4.204 & 4.315 & 63.071 & 2.343 & 3.245 & 1.016 \\
\hline$\# 8$ & 5.483 & 3.489 & 3.015 & 2.376 & 4.651 & 3.089 & 2.531 & 4.241 & 57.103 & 5.217 & 3.763 & 5.041 \\
\hline$\# 9$ & 5.571 & 4.213 & 2.981 & 2.969 & 4.539 & 3.151 & 4.048 & 4.151 & 53.980 & 4.728 & 2.705 & 6.964 \\
\hline$\# 10$ & 4.983 & 4.843 & 2.749 & 2.847 & 4.769 & 3.934 & 3.547 & 3.478 & 52.704 & 6.243 & 4.732 & 5.170 \\
\hline$\# 11$ & 6.620 & 4.093 & 3.695 & 4.229 & 4.326 & 3.566 & 3.573 & 4.118 & 51.122 & 6.645 & 3.599 & 4.414 \\
\hline$\# 12$ & 5.632 & 4.718 & 3.865 & 3.765 & 6.846 & 2.910 & 3.896 & 4.101 & 49.432 & 6.331 & 4.004 & 4.500 \\
\hline$\# 13$ & 5.973 & 6.074 & 3.987 & 3.591 & 6.635 & 3.429 & 3.356 & 4.073 & 46.374 & 6.315 & 3.727 & 6.466 \\
\hline$\# 14$ & 5.732 & 8.436 & 4.745 & 4.310 & 7.008 & 3.463 & 3.745 & 3.348 & 43.054 & 5.734 & 3.203 & 7.221 \\
\hline$\# 15$ & 7.613 & 7.883 & 4.542 & 4.070 & 6.466 & 4.598 & 3.756 & 3.845 & 40.447 & 6.268 & 4.328 & 6.186 \\
\hline$\# 16$ & 8.532 & 7.188 & 5.055 & 4.188 & 6.095 & 4.460 & 4.640 & 4.898 & 38.534 & 6.238 & 4.005 & 6.165 \\
\hline$\# 17$ & 7.919 & 6.775 & 5.614 & 5.108 & 5.510 & 4.167 & 5.291 & 5.191 & 36.580 & 8.490 & 3.861 & 5.494 \\
\hline$\# 18$ & 9.780 & 7.238 & 4.839 & 5.015 & 5.117 & 4.185 & 7.739 & 4.760 & 33.395 & 7.863 & 4.534 & 5.534 \\
\hline$\# 19$ & 9.934 & 9.153 & 4.439 & 5.147 & 5.967 & 4.174 & 6.888 & 6.332 & 29.145 & 9.181 & 3.936 & 5.704 \\
\hline$\# 20$ & 18.715 & 9.008 & 4.455 & 5.239 & 6.526 & 5.159 & 6.653 & 6.011 & 18.094 & 10.195 & 4.259 & 5.686 \\
\hline$\# 21$ & 10.710 & 11.913 & 6.148 & 6.306 & 8.196 & 8.778 & 6.922 & 8.421 & 9.420 & 9.742 & 4.718 & 8.726 \\
\hline$\# 22$ & 7.282 & 6.994 & 9.357 & 9.845 & 9.299 & 8.446 & 9.369 & 7.786 & 6.427 & 9.813 & 6.910 & 8.473 \\
\hline$\# 23$ & 5.544 & 5.667 & 10.945 & 10.206 & 8.092 & 8.378 & 11.049 & 9.100 & 6.514 & 5.158 & 10.235 & 9.112 \\
\hline$\# 24$ & 4.884 & 5.237 & 9.984 & 9.066 & 7.505 & 8.409 & 6.989 & 9.669 & 6.433 & 4.219 & 20.474 & 7.130 \\
\hline
\end{tabular}

Based on the above, we can argue that for policymakers it is relevant to focus on physical infrastructure as an important factor in the entrepreneurial ecosystem. Indeed, this is a central factor for the success of all businesses, especially new and growing firms. Von Bargen et al. (2003) argue that the creation of "robust and reliable" infrastructure has been needed to boost the United States (US) economy over the last half century. This includes the interstate highway system, airports, seaports, and telecommunication systems. For new businesses seeking to gain market access, the ability to respond quickly to consumer demand is crucial for their growth and survival. Sound transport and water and sewage systems are likely to confer an advantage for territories over regions with inadequate or outdated infrastructure. In addition, the importance of telecommunications systems, in particular the need for broadband, continues to grow as companies become more dependent on technology in their day-today operations. The link between infrastructure and entrepreneurship has been widely studied by Audretsch et al. 
(2015). In their analysis, they argue that infrastructure enhances connectivity and linkages, facilitating the recognition of entrepreneurial opportunities and the ability of entrepreneurs to actualize such opportunities. Moreover, they suggest that start-up activity is positively related to infrastructure in general, but that certain specific types of infrastructure, such as broadband, are more strategically significant than highways and railroads.

Having verified the power of SMAA in comparing European entrepreneurial ecosystems and gained information on the strengths and weaknesses for a certain sample of these, the analysis continues with the investigation of the relation between entrepreneurial ecosystem factors and growth-oriented start-ups.

As already shown, we base the evaluation of the countries considered on 12 different entrepreneurial ecosystem factors. Therefore, considering the ranking of the countries in relation to the ecosystem output, that is the number of high-growth start-ups $\left(\right.$ Ranking $_{S t-u p}$ ), we aim to identify the ranking of criteria (w.r.t. their importance) such that the corresponding country ranking is the most similar to Ranking $g_{\text {St-up }}$.

In a first step, we analyze the correlation between the ranking of the countries considered in relation to each factor and Ranking $g_{S t-u p}$ to establish if a single factor is sufficient to explain Ranking St-up $_{\text {. Therefore, for each }}$ factor, we compute the corresponding ranking, Ranking ${ }_{\text {Factor }}$, and the correlation between Ranking Factor $_{\text {and }}$ Ranking ${ }_{S t-u p}$, analyzed by means of the Kendall tau coefficient.

Table 8 Kendall tau correlation coefficient between Ranking ${ }_{S t-u p}$ and the ranking obtained for each factor, Ranking Factor

\begin{tabular}{|lr|}
\hline Entrepreneurial ecosystem factors & Kendall tau value \\
\hline FINANCE & -0.091 \\
POLICY & 0.004 \\
REGUL & 0.162 \\
PROGRAM & -0.542 \\
EDU & 0.123 \\
H-EDU & -0.178 \\
TRANSFER & -0.146 \\
COMMER & -0.209 \\
DYNAMICS & 0.012 \\
OPENNESS & -0.115 \\
PHYSICAL & -0.028 \\
CULTURE & -0.146 \\
\hline
\end{tabular}

As shown in Table 8, the highest correlation (0.162) is obtained between Ranking St-up $_{\text {and the ranking }}$ obtained for "National Policy Regulation." This value is not particularly high, meaning that Ranking $g_{S t-u p}$ cannot be explained by considering a single factor only. Therefore, we aim to identify the most important factors able to explain Ranking $g_{S t-u p}$. Moreover, half the factors have a negative value for the Kendall tau correlation coefficient, showing an inverse correlation between certain factors with respect to performance measured in terms of start-ups. For this reason, we apply the methodology described in section 3. Considering the 12 factors, all possible rankings of importance (technically, all their permutations) number $12 !=490,001,600$. Consequently, we obtain 12 ! possible country rankings, and for each of these we compute the correlation with Ranking $_{S t-u p}$ using the Kendall tau coefficient.

The maximal Kendall value (equal to 0.581 ) is obtained for 175 different factor rankings that provide exactly the same country rankings. Therefore, considering these 175 rankings of importance for the 12 factors, we compute the frequency with which each factor fills a certain ranking position. The value of the Kendall tau is very high, and this shows that a composite index is able to capture the correlation between the 12 factors and the performance of the countries measured in terms of new start-ups much better than the single factors taken alone. Moreover, the results of Table 9 show that the conjoint consideration of all the factors avoids a misleading representation of the influence that each factor has on performance. Indeed, "Cultural and Social Norms" is always the most important factor in all rankings of importance, followed by "Government Programs" and 
"Internal Market Dynamics," which are always the second and the third most important factors, respectively. Let us compare these results with those shown in Table 8. It can be observed that with respect to the number of new start-ups, the Kendall tau values for the single factors show a negative correlation for "Culture" (-0.146), a strong negative correlation for "Government Programs" (-0.542), and a positive but quite weak correlation for "Internal Market Dynamics" (0.012). This confirms that only the conjoint consideration of the importance of the factors proposed by SMAA-S can provide a realistic view of their various roles. In contrast, considering each of the factors independently, as in Table 8, leads to the risk of presenting a misleading picture of the whole context.

Table 9 Frequency of factors in terms of importance

\begin{tabular}{|l|c|c|c|c|c|c|c|c|c|c|c|c|}
\hline & $\mathbf{\# 1}$ & $\mathbf{\# 2}$ & $\mathbf{\# 3}$ & $\mathbf{\# 4}$ & $\mathbf{\# 5}$ & $\mathbf{\# 6}$ & $\mathbf{\# 7}$ & $\mathbf{\# 8}$ & $\mathbf{\# 9}$ & $\mathbf{\# 1 0}$ & $\mathbf{\# 1 1}$ & $\mathbf{\# 1 2}$ \\
\hline FINANCE & 0 & 0 & 0 & 0 & 0 & 0 & 0 & 14.86 & 23.43 & 25.71 & 21.14 & 14.86 \\
\hline POLICY & 0 & 0 & 0 & 0 & 0 & 24.57 & 37.71 & 24.00 & 6.29 & 6.86 & 0.57 & 0 \\
\hline REGUL & 0 & 0 & 0 & 0 & 0 & 4.00 & 10.29 & 16.57 & 21.71 & 28.57 & 15.43 & 3.43 \\
\hline PROGRAM & 0 & 100.00 & 0 & 0 & 0 & 0 & 0 & 0 & 0 & 0 & 0 & 0 \\
\hline EDU & 0 & 0 & 0 & 0 & 4.00 & 32.57 & 38.29 & 18.86 & 5.71 & 0.57 & 0 & 0 \\
\hline H-EDU & 0 & 0 & 0 & 5.71 & 16.00 & 14.29 & 12.57 & 22.29 & 9.71 & 10.29 & 6.29 & 2.86 \\
\hline TRANSFER & 0 & 0 & 0 & 0 & 0 & 0 & 0 & 2.86 & 16.00 & 14.29 & 26.29 & 40.57 \\
\hline COMMER & 0 & 0 & 0 & 84.57 & 14.86 & 0.57 & 0 & 0 & 0 & 0 & 0 & 0 \\
\hline DYNAMICS & 0 & 0 & 100.00 & 0 & 0 & 0 & 0 & 0 & 0 & 0 & 0 & 0 \\
\hline OPENNESS & 0 & 0 & 0 & 0 & 0 & 0 & 0 & 0.57 & 17.14 & 13.71 & 30.29 & 38.29 \\
\hline PHYSICAL & 0 & 0 & 0 & 9.71 & 65.14 & 24.00 & 1.14 & 0 & 0 & 0 & 0 & 0 \\
\hline CULTURE & 100.00 & 0 & 0 & 0 & 0 & 0 & 0 & 0 & 0 & 0 & 0 & 0 \\
\hline
\end{tabular}

We consider that the results obtained with SMAA-S are highly relevant, and thus wish to comment on them in greater detail. "Culture" is the main factor in terms of the correlation between the entrepreneurial ecosystem and the emergence of new growth-oriented enterprises. Leading entrepreneurial ecosystems include the strength of cultural support for entrepreneurship. Several studies (e.g., Chua et al. 2015; Wyrwich 2012) show how national culture shapes potential entrepreneurs' propensity to create businesses and to innovate. In certain countries, "entrepreneurship capital” emerges (Audretsch and Keilbach 2004; Del Giudice et al. 2017). This is a form of capital present in the territory that is conducive to the creation of new ventures and is closely related to the domain of an entrepreneurial culture. Culture seems to be persistent over time as institutions, norms, individual beliefs, and actions, as well as economic outcomes, mutually reinforce each other (Jha 2008). In the study conducted by Neck et al. (2004), entrepreneurial culture was considered beneficial and critical to the development of the local environment, albeit being the most difficult element of an ecosystem in terms of management and replication. An entrepreneurial culture can positively influence the intention to become an entrepreneur, the propensity to start a new firm, and the economic success of endogenous start-ups (Nicotra et al. 2017).

In line with previous studies, our analysis concludes that entrepreneurial culture is closely related to growth-oriented entrepreneurship through a holistic analysis that simultaneously considers various factors of an entrepreneurial ecosystem. In addition, according to our results, government policy and the regulatory framework are also found to be likely to accelerate or inhibit the starting and scaling phases of early-stage companies. In this regard, some components of the government and regulatory framework concern the ease of starting a business, tax incentives, business-friendly legislation/policies, and new firms' access to infrastructure. Klapper et al. (2009) describe how regulations related to innovation and starting a new firm can affect entrepreneurial activity. More recently, Kuratko and Menter (2017) have described the role of public policy in fostering technology-based nascent entrepreneurship. Policymakers can support entrepreneurship with policies or programs aimed at modifying regulations, such as easing business environment constraints, expanding access to credit, or promoting value chain integration (De Mel et al. 2009; McKernan 2002; Paulson and Townsend 2004). Specifically, governments are becoming increasingly interested in fostering a favorable atmosphere for entrepreneurship through tax rates and incentives, as well as providing other forms of affirmative financial support and eliminating bureaucratic procedures hindering business creation, such as those often associated with applying for permits and licenses (Porter 1998; Siegel et al. 2003). Djankov et al. (2002) undertook a study on the effect of the regulation of the entry of start-ups on the economic performance of 85 countries, finding positive and significant results. Once again, our study differs from the others because it identifies government 
policy and the regulatory framework as the second most effective factors among all those considered in the business ecosystem able to support the emergence of new growth-oriented businesses.

Finally, from the results of the empirical analysis, internal market dynamics comprise the third factor in the entrepreneurial ecosystem closely related to the emergence of new companies in the country of reference. Market dynamism can be defined as the degree of change in the market (Achrol and Stern 1988; Jap 1999). The dynamism of the market has generally been studied as one of the key factors influencing company performance and innovation (Chan et al. 2016; Schilke 2014). Kamasak et al. (2016) aimed to investigate the moderating effect of market dynamism in the relationship between knowledge management and innovation. Their results show that higher levels of market dynamism make the link stronger. According to Park and Ryu (2015), dynamism moderates the relationship between technology commercialization and business results. Schilke (2014) proposed a moderate U-shaped effect of market dynamism in the relationship between new product development capabilities and competitive advantage, and tested this with data from 279 companies. Schilke's results show that the development of new product is associated to a greater extent with competitive advantage in moderately dynamic markets than in stable or highly dynamic markets.

To the best of our knowledge, this is the first empirical study to confirm the relation between internal market dynamics, as a factor of the entrepreneurial ecosystem, and the birth of high-growth firms. The key factors of this dynamism are rapid changes in technology, changes in the market structure, market instability, wide fluctuations in the supply of materials, and the probability of market shocks (Jansen et al. 2006; Sirmon et al. 2007). The dynamism of the market is characterized by volatility and unpredictability (Miller and Friesen, 1983). In an environment with a high level of market dynamism, it is not easy to distinguish the boundaries of the market, or to develop successful business models, identify competitors, customers, and suppliers (Eisenhardt and Martin 2000). Existing businesses tend to suffer from external uncertainties that make it more difficult to forecast, plan, and organize their resources (Jansen et al. 2006). Indeed, businesses are required to improve and modify their products and services continuously through innovation to meet customer needs in a highly dynamic market. In the context of a highly dynamic market, companies are required constantly to analyze customer preferences, expand information boundaries, and develop quick responses in handling customer needs appropriately, coping with the turbulence in the market and staying competitive. Such dynamism creates economic spaces that are constantly expanding. In a dynamic market, reactions must be faster and interactions more frequent. Therefore, dynamism leaves the field open to entrepreneurial and innovative actors, such as startups. Moreover, under vigorous stimuli, dynamism grows yet further through the creation of virtuous circuits of new innovative companies. This is why new companies are best suited to operate in dynamic markets, being capable of rapidly developing and enacting effective know-how. In turn, dynamic markets have great potential for growth. This is growth that is heavily driven by new firms, which play a fundamental and often innovative role, changing the balance in the market, and constantly re-launching competitive challenge through strategic initiatives. Such a process creates competitiveness and adds value to the ecosystem itself.

\section{Concluding remarks}

Entrepreneurship derives not only from the attitudinal factors of potential entrepreneurs, such as attitude toward risk, but also from environmental factors. The so-called entrepreneurial ecosystem, formed by factors such as financial support, national policy, R\&D transfer, education, and cultural and social norms can facilitate or hinder business activity, resulting in incentives or deterrents when starting new entrepreneurial initiatives. The international comparison between national entrepreneurial ecosystems is important in highlighting the strengths and weaknesses of a country, defining its entrepreneurial enabling or inhibiting factors. However, academic research has failed to keep up with benchmarking entrepreneurial ecosystems as an element for guiding national competitiveness.

Starting from these concepts, this paper applies a specific methodology, namely SMAA, to a dataset on entrepreneurial ecosystems to rank European countries. SMAA provides a probabilistic ranking that is more reliable than the usual single ranking obtained through composite indices built with a single specific weight vector. Indeed, in considering a single weight vector, which can be a falsely objective equal weight vector, one considers only one perspective, and therefore loses the possibility of taking into account the various perspectives available. Instead, taking into account several weight vectors, one can appreciate the fact that some countries could be in optimal position in terms of certain weight vectors, while other countries could be in optimal position in relation to other weight vectors. Therefore, we have to account for the probability of attaining a given ranking 
position rather than a specific, well-defined and precise ranking position attained by each country. In our research, we considered a random sample of 1,000,000 weight vectors assigned to the 12 entrepreneurial ecosystem factors permitting us to explore the performance of the entrepreneurial ecosystems of European countries from a broad plurality of perspectives, each corresponding to one of the weight vectors considered.

The analysis demonstrates the utility of SMAA. In particular, it is able to make a substantial contribution to achieving robust evaluations of entrepreneurial ecosystems, moving from "subjective objectivity" toward more "objective subjectivity" (Greco et al. 2017). Essentially, SMAA can objectively take into consideration the "inner subjectivity" of all evaluations derived from the aggregation of different factors with the full spectrum of different weighting choices. Moreover, taking into consideration GEM data and applying SMAA, the paper explains how to uncover patterns of territorial disparities in European countries more clearly than in the extant empirical literature.

SMAA also makes it possible to determine which factors can be considered strengths and weaknesses for each country compared to others. Indeed, if a country attains the best positions when the greatest importance is assigned to certain factors, this means that those factors are its strengths, and it is reasonable to design policies that are mainly based on these factors. If, however, a country is ranked in the worst positions based on greater weight given to certain other factors, these are its weak points and it can be recommended that they accord lower relevance to these factors in the policies adopted.

In addition, we have aimed to fill another gap in the academic literature. The recent literature on entrepreneurial ecosystems has addressed the definition of which factors are most important for the entrepreneurial success of ecosystems. Cohen (2006), Isenberg (2011), and Feld (2012), among others, have provided some lists of relevant elements characterizing effective entrepreneurial ecosystems. They aim to define which factors of the ecosystem, more than others, are the determinants of the birth and scaling up of businesses. Such literature is largely based on the direct experiences of researchers, but does not empirically embrace the relation between ecosystem factors and high-growth start-ups in a territory.

Therefore, deriving once again some assumptions from the SMAA methodology, we developed SMAA-S. This new methodology was applied to the study of the relation between entrepreneurial ecosystems and highgrowth start-ups. In this way, interesting results were obtained concerning which factors can be considered relevant in a territory for reaching a high level of growth-oriented start-ups.

From the empirical analysis, the most relevant entrepreneurial ecosystem factors enabling the activity of high-growth firms were identified as "Cultural and Social Norms," "Government Programs," and "Internal Market Dynamics." This result, obtained with the newly proposed SMAA-S methodology, is in line with what we expected. It confirms the promising perspectives for the future use of SMAA-S in analogous investigations. Based on our results, let us further comment on the importance of culture for the vitality of entrepreneurial ecosystems. The culture of a country is related to the desirability of people becoming entrepreneurs, the propensity to start a new firm, and the economic success of endogenous start-ups. A country's entrepreneurial start-up rate appears to be a measure of the country's entrepreneurial culture. Moreover, government policy and the regulatory framework are also found to be related to the birth and scaling phases of firms. In this regard, some components of the government and regulatory framework relate to the ease of starting a business, tax incentives, and business-friendly legislation/policies. Finally, from the results of the empirical analysis, internal market dynamics comprise the third factor in entrepreneurial ecosystems closely related to the emergence of new companies in the country of reference. Market dynamism can be defined as the degree of change in the market (Achrol and Stern 1988; Jap 1999). Dynamism leaves some areas of the market open to entrepreneurial and innovative actors. This is why new companies are best suited to operate in dynamic markets, capable of rapidly developing and enacting effective know-how. Under the vigorous stimulus of start-ups, dynamism grows yet further by creating virtuous circuits based on new innovative companies.

To sum up, we can state that the paper contributes in different ways to the literature on entrepreneurial ecosystem. First of all, it assesses an accurate and reliable technique for measuring and comparing entrepreneurial ecosystems in order to help territories realize their strengths and weaknesses and understand how to shape their own entrepreneurial ecosystem. Moreover, it identifies through a robust empirical analysis some factors (Cultural and Social Norms, Government Programs and Internal Market dynamic) that could be considered as the most significant for the entrepreneurial success of ecosystems, contributing to a literature that until now has been based on the direct experiences of researchers on few qualitative case studies or without empirical evidence. 
Finally, the paper contributes to the literature on entrepreneurial ecosystems by investigating the relation between factors of an ecosystem and their output, that is the number of growth-oriented startups, filling a gap emphasized by various authors as a weakness of such a literature (see Alvedalen and Boschma 2017; Stam 2015; Stam and Spigel 2017).

From the present analysis, policymakers can derive information both in relation to the entrepreneurial ecosystem of their own country and, in general, in relation to the most important environmental factors affecting entrepreneurship.

Concerning the first aspect, measuring, understanding and comparing the entrepreneurial ecosystem of their own country is critical to momentum and maturity of policy makers. Specific indications have been provided in the paragraph 5 referring to Italy. We have offered information on a specific Countriy that could help policymakers define appropriate strategies to enhance and sustain strengths and to protect from the negative effects of weaknesses. This put the country in a position that enables it to attain better performance with respect to other countries. In addition, the paper provides policymakers with robust general indications on the most relevant factors affecting entrepreneurship. Specifically, it encourages policymakers to define ad hoc "Government Programs", to promote the establishment and the growth of new innovative enterprises with a high technological value. Policymakers maintain ecosystems; they shape the regional dynamics, and they can also provide smart funding that amplifies private investments. The level and quality of regulation has a big impact on lowering the threshold for entrepreneurship. In addition, the paper suggests policymakers to invest in disseminating entrepreneurial "culture". This means investing in education, vocational education and training, defining proactive communication and networking strategies addressed to create an entrepreneurship mindset among the population.

The article makes the link between entrepreneurial ecosystem and start-ups more evident. It follows that, the levers used by policymakers to improve the entrepreneurial ecosystems in a Country, in turns, affects the creation and growth of start-ups, generating specific economic, technologic and societal impacts in the long term. First, start-ups are positively related to job creation (Acs and Mueller 2008; Fritsch 2013, Fritsch and Mueller 2008). Higher start-up rates are associated with higher immediate levels of employment. Additionally, this impacts on technology because start-ups generate innovation, the exploration of new markets, and define the way for the jobs of the future. Because of the reluctance of incumbent firms in adopting new ideas, interested in exploiting the profit possibilities of their extant products, start-ups are the most promising possibilities for inventors to exploit their knowledge (Audretsch 1995; Klepper 2009). Finally, promoting entrepreneurial ecosystem and so entrepreneurship increases competition boosting the efficiency of a market and improving people's welfare. If the products of a newcomer differ from those of the incumbent, or if an entrant introduces significant process innovation, the result will be a greater variety of available goods and problem-solving methods. This implies a higher likelihood that customers will find a better match for their preferences. Increased variety due to new supplies may intensify the division of labour, follow-up innovation, and generating significant economic development (Boschma 2004; Saviotti and Pyka 2004).

The paper has some limitations. Specifically, it is based on GEM data. GEM is considered a valid and reliable source of data, but values related to entrepreneurial ecosystem factors are assigned to each country based on the views of a pool of experts. Therefore, there is an implicit bias that derives from the subjectivity of expert evaluations.

Future research could validate such results by applying SMAA and SMAA-S to various other entrepreneurial ecosystem factors. It should also be observed that the analysis is based on the evaluations of the countries considered with respect to each factor reported for a single year, namely 2017. Thus, it would be interesting to develop a dynamic analysis studying how the computed data evolve over time. Future research could certainly investigate this topic. Another issue that could be taken into account is the consideration of more advanced models that permit analysis of the possible interaction between factors (Angilella et al. 2015). Finally, we hope that in taking inspiration from this contribution, future studies might apply SMAA and SMAA-S to the managerial field, making a substantial contribution to the evolution of the discipline.

\section{References}

Achrol, R. S., \& Stern, L. W. (1988). Environmental determinants of decision-making uncertainty in marketing channels. Journal of Marketing Research, 25(1), 36-50. 
Acs, Z. J., \& Mueller, P. (2008). Employment effects of business dynamics: Mice, gazelles and elephants. Small Business Economics, 30, 85-100.

Acs, Z. J., Parsons, W., \& Tracy, S. (2008). High impact firms: Gazelles revisited. Office of Advocacy Working Paper, US Small Business Administration.

Alvedalen, J., \& Boschma, R. (2017). A critical review of entrepreneurial ecosystems research: Towards a future research agenda. European Planning Studies, 25(6), 887-903.

Angilella, S., Corrente, S., \& Greco, S. (2015). Stochastic multiobjective acceptability analysis for the Choquet integral preference model and the scale construction problem. European Journal of Operational Research, 240, 172-182.

Angilella, S., Bottero, M., Corrente, S., Ferretti, V., Greco, S., \& Lami, I. (2016). Non additive robust ordinal regression for urban and territorial planning: An application for siting an urban waste landfill. Annals of Operations Research, 245(1), 427-456.

Audretsch, D. (1995). Innovation, growth and survival. International Journal of Industrial Organization, 13

(4), 441-457.

Audretsch, D. B., \& Belitski, M. J (2017). Entrepreneurial ecosystems in cities: Establishing the framework conditions. The Journal of Technology Transfer, 42(5), 1030-1051.

Audretsch, D. B., \& Fritsch, M. (1994). On the measurement of entry rates. Empirica, 21, 105-113.

Audretsch, D. B., \& Keilbach M. (2004). Does entrepreneurship capital matter? Entrepreneurship Theory and Practice, 28(5), 419-429.

Audretsch, D. B., Heger, D., \& Veith T. (2015). Infrastructure and entrepreneurship. Small Business Economics, 44(2), 219-230.

Birch, D. L., Medoff, J., Solmon, L. C., \& Levenson, A.R. (1994). Gazelles, labor markets, employment policy and job creation. Boulder, $\mathrm{CO}$ and London, UK: Westview Press.

Boschma, R. (2004). Competitiveness of regions from an evolutionary perspective. Regional Studies, 38, 10011014.

Brüderl, J., \& Preisendörfer, P. (2000). Fast-growing businesses: Empirical evidence from a German study. International Journal of Sociology, 30(3), 45-70.

Bruyat, C., \& Julien, P. A. (2000). Defining the field of research in entrepreneurship. Journal of Business Venturing, 16, 165-180.

Carayannis, E. G., Provance, M., \& Grigoroudis, E. J. (2016). Entrepreneurship ecosystems: An agent-based simulation approach. The Journal of Technology Transfer, 41(3), 631-653.

Carree, M. A., \& Thurik, A. R. (2008). The lag structure of the impact of business ownership on economic performance in OECD countries. Small Business Economics, 30(1), 101-110.

Chapman, T. (2011). Building an entrepreneurial ecosystem: lesson from Omaha. Amanda Styron Community Builder Editor.

Chan, H. K., Yee, R. W., Dai, J., \& Lim, M. K. (2016). The moderating effect of environmental dynamism on green product innovation and performance. International Journal of Production Economics, 181(2), 384391.

Charnes, A., Cooper W., \& Rhodes, E. (1987). Measuring the efficiency of decision making units. European Journal of Operational Research, 2, 429-444.

Chua, R. Y., Roth, Y., \& Lemoine, J. F. (2015). The impact of culture on creativity: How cultural tightness and cultural distance affect global innovation crowdsourcing work. Administrative Science Quarterly, 60, 189227.

Cohen, B. (2006). Sustainable valley entrepreneurial ecosystems. Business Strategy Environment, 15, 1-14.

Cunningham, J., \& O'Kane, C (2017). Technology based nascent entrepreneurship. London: Palgrave Macmillan.

Davidsson, P. (2004). Researching entrepreneurship. International Studies in Entrepreneurship. Boston, MA: Springer.

Davidsson, P., \& Henrekson, M. (2002). Determinants of the prevalence of start-ups and high-growth firms. Small Business Economics, 19(2), 81-104.

Dejardin, M. (2011). Linking net entry to regional economic growth. Small Business Economics, 36, 443-460. 
Del Giudice, M., Nicotra, M., Romano, M., \& Schillaci, C. E. (2017). Entrepreneurial performance of principal investigators and country culture: Relations and influences. The Journal of Technology Transfer, 42(2), 320-337.

Delmar, F., Davidsson, P., \& Gartner, W. B. (2003). Arriving at the high-growth firm. Journal of Business Venturing, 18(2), 189-216.

De Mel, S., McKenzie, D., \& Woodruff, C. (2009). Measuring microenterprise profits: Must we ask how the sausage is made? Journal of Development Economics, 88(1), 19-31.

Dennis, W. J., Jr. (1997). More than you think: An inclusive estimate of business entries. Journal of Business Venturing, 12, 175-196.

Dennis, W. J., Jr. (1999). Business starts and stops. Wells Fargo/NFIB Series, Washington, DC: The NFIB Education Foundation, November.

Djankov, S., La Porta, R., Lopez-de-Silanes, F., \& Shleifer, A. (2002). The regulation of entry. Quarterly Journal of Economics, 117(1), 1-37.

Eisenhardt, K. M., \& Martin, J. A. (2000). Dynamic capabilities: What are they? Strategic Management Journal, 21(10-11), 1105-1121.

Feld, B. (2012). Start-up communities: Building an entrepreneurial ecosystem in your city. Hoboken, NJ: Wiley InterScience.

Fischer, M. M., \& Nijkamp, P. (1988). The role of small firms for regional revitalization. The Annals of Regional Science, 22(1), 28-42.

Fritsch, M. (2013). New business formation and regional development-A survey and assessment of the evidence. Foundations and Trends in Entrepreneurship, 9, 249-364.

Fritsch, M., \& Mueller, P. (2008). The effect of new business formation on regional development over time.

The case of Germany. Small Business Economics, 30(1), 15-29.

Gartner, W. B. (1990). What are we talking about when we talk about entrepreneurship? Journal of Business Venturing, 5(1), 15-28.

Gartner, W. B., \& Shane, S. A. (1995). Measuring entrepreneurship over time. Journal of Business Venturing, 10(4), 283-301.

GEM (2017). Global Report 2016/17. http://www.gemconsortium.org/report/49812

Greco, S., Matarazzo, B., \& Słowiński, R. (2001). Rough set theory for multicriteria decision analysis. European Journal of Operational Research, 129(1), 1-47.

Greco, S., Figueira, J. R., \& Ehrgott, M. (2016). Multiple criteria decision analysis: State of the art surveys. Berlin: Springer.

Greco, S., Ishizaka, A., Matarazzo, B., \& Torrisi, G. (2017). Stochastic multiattribute acceptability analysis: An application to the ranking of Italian regions. Regional Studies. DOI: 10.1080/00343404.2017.1347612.

Greco, S., Ishizaka, A., Tasiou, M., Torrisi, G. (2018) On the methodological framework of composite indices: a review of the issues of weighting, aggregation, and robustness. Social Indicators Research. https://doi.org/10.1007/s11205-017-1832-9.

Halabisky, D., Dreessen, E., \& Parsley, C. (2006). Growth in firms in Canada 1985-1999. Journal of Small Business and Entrepreneurship, 19(3), 255-268.

Harrington, K. (2016) Is Your Entrepreneurial Ecosystem Scaling? An Approach To Inventorying And Measuring A Region's Innovation Momentum. Innovations 11 (1), 126-142.

Hébert, R. F., \& Link, A. N. (1989). In search of the meaning of entrepreneurship. Small Business Economics, 1(1), 39-49.

Isenberg, D. J. (2010). How to start an entrepreneurial revolution. Harvard Business Review, 88(6), 41-50.

Isenberg, D. J. (2011). The entrepreneurship ecosystem strategy as a new paradigm for economy policy: principles for cultivating entrepreneurship. Babson Entrepreneurship Ecosystem Project. Babson Park, MA: Babson College.

Jansen, J. J. P., Van Den Bosch, F. A. J., \& Volberda, H. W. (2006). Exploratory innovation, exploitative innovation, and performance: Effects of organizational antecedents and environmental moderators. Management Science, 52(11), 1661-1674.

Jap, S. D. (1999). Pie-expansion efforts: Collaboration processes in buyer-supplier relationships. Journal of Marketing Research, 36(4), 461-475. 
Jha, S. (2008). Trade, institutions and religious tolerance: Evidence from India. Stanford University Research Paper, no. 2004. https://papers.ssrn.com/sol3/papers.cfm?abstract_id=948734

Kamasak, R., Yavuz, M., \& Altuntas, G. (2016). Is the relationship between innovation performance and knowledge management contingent on environmental dynamism and learning capabilities? Evidence from a turbulent market. Business Research, 9(2), 229-253.

Karatas- Ozkan, M., Anderson, A. R., Fayolle, A., Howells, J., Condor, R. (2014). Understanding entrepreneurship: Challenging dominant perspectives and theorizing entrepreneurship through new postpositivist epistemologies. Journal of Small Business Management, 52, 589-593.

Keeney, R. L., \& Raiffa, H. (1976). Decisions with multiple objectives: Preferences and value tradeoffs. New York, NY: Wiley.

Kendall, M. (1938). A new measure of rank correlation. Biometrika, 30(1-2), 81-89.

Klapper, L., Lewin, A., \& Delgado, J. M. Q. (2009). The impact of the business environment on the business creation process. World Bank, Development Research Group, Finance and Private Sector Team, Policy Research Working Paper, no. 4937. World Bank.

Klepper, S. (2009). Spinoffs: A review and synthesis. European Management Review, 6, 159-171.

Kuratko, D. F., \& Menter, M. (2017). The role of public policy in fostering technology-based nascent entrepreneurship. In J. Cunningham \& C. O'Kane (Eds.), Technology based nascent entrepreneurship (pp. 19-52). New York: Palgrave Macmillan.

Lahdelma, R., Hokkanen, J., \& Salminen, P. (1998). SMAA - Stochastic multiobjective acceptability analysis. European Journal of Operational Research, 106(1), 137-143.

Lahdelma, R., Salminent, P., \& Hokkanen, J. (2002). Locating a waste treatment facility by using stochastic multicriteria acceptability analysis with ordinal criteria. European Journal of Operational Research, 142(2), 345-356.

Leskinen, P., Viitaned, J., Kangas, A., \& Kangas, J. (2006). Alternatives to incorporate uncertainty and risk attitude in multicriteria evaluation of forest plans. Forest Science, 52(3), 304-312.

Littunen, H., \& Tohmo, T. (2003). The high growth in new metal-based manufacturing and business service firms in Finland. Small Business Economics, 21(2), 187-200.

Malecki, E. J. (2011). Connecting local entrepreneurial ecosystems to global innovation networks: Open innovation, double networks, and knowledge integration. International Journal of Entrepreneurship and Innovation Management, 14, 36-59.

McKernan, S. M. (2002). The impact of microcredit programs on self-employment profit: Do non-credit program aspects matter? The Review of Economics and Statistics, 84(1), 93-115.

Miller, D., \& Friesen, P. (1983). Strategy-making and environment: The third link. Strategic Management Journal, 4(3), 221-235.

Napier, G., \& Hansen, C. (2011). Ecosystems for young scaleable firms. FORA Group.

Neck, H. M., Meyer, G. D., Cohen, B., \& Corbett, A. C. (2004). An entrepreneurial system view of new venture creation. Journal of Small Business Management, 42, 190-208.

Nicotra, M., Romano, M., Del Giudice, M., \& Schillaci, C. E. (2017). The causal relation between entrepreneurial ecosystem and productive entrepreneurship. Journal of Technology Transfer. DOI: 10.1007/S10961-017-9628-2.

OECD (1998). Fostering entrepreneurship, the OECD jobs strategy. Paris: Organization for Economic Cooperation and Development.

OECD (2000). Education at a glance 2000: OECD indicators. Paris: Organization for Economic Co-operation and Development.

OECD (2016). Entrepreneurship at a glance 2016. Paris: Organization for Economic Co-operation and Development.

Paelinck, J. H. P. (1974). Qualitative multiple-criteria analysis, environmental protection and multiregional development. Papers of the Regional Science Association, 36, 59-74.

Park, T., \& Ryu, D. (2015). Drivers of technology commercialization and performance in SMEs: The moderating effect of environmental dynamism. Management Decision, 53(2), 338-353.

Paulson, A. L., \& Townsend, R. (2004). Entrepreneurship and financial constraints in Thailand. Journal of Corporate Finance, 10, 229-236. 
Piergiovanni, R., Carree, M. A., \& Santarelli, E. (2012). Creative industries, new business formation, and regional economic growth. Small Business Economics, 39, 539-560.

Porter, M. (1990). The competitive advantage of nations. New York, NY: The Free Press.

Porter, M. (1998). Clusters and the new economics of competition. Harvard Business Review, NovemberDecember, 77-89.

Roy, B. (1996). Multicriteria methodology for decision aiding. Dordrecht: Kluwer.

Roundy, P. T., Brockman, B. K., Bradshaw, M. (2017). The resilience of entrepreneurial ecosystems. Journal of Business Venturing Insights, 8, 99-104.

Saviotti, P. P., \& Pyka, A. (2004). Economic development, variety and employment. Revue Economique, 55,

1023-1049

Schilke, O. (2014). On the contingent value of dynamic capabilities for competitive advantage: The nonlinear moderating effect of environmental dynamism. Strategic Management Journal, 35(2), 179-203.

Schillaci, C. E., \& Nicotra, M. (2010). Rowing against the tide: The struggle to enhance entrepreneurship in a hostile region. In G. Dossena (Ed.), Entrepreneurship today (pp.143-162). Milano: McGraw-Hill.

Shane S., \& Venkataraman, S. (2000). The promise of entrepreneurship as a field of research. Academy of Management Review, 25(1), 217-226.

Siegel, D. S., Westhead, P., \& Wright, M. (2003). Science parks and the performance of new technology-based firms: A review of recent UK evidence and an agenda for future research. Small Business Economics, 20(2), 177-184.

Sirmon, D. G., Hitt, M. A., \& Ireland, D. (2007). Managing firm resources in dynamic environments to create value: Looking inside the black box. Academy of Management Review, 32(1), 273-292.

Spigel, B. (2017). The relational organization of entrepreneurial ecosystems. Entrepreneurship Theory and Practice, 41(1), 49-72.

Stam, E. (2015). Entrepreneurial ecosystems and regional policy: A sympathetic critique. European Planning Studies, 23(9), 1759-1769.

Stam, E., \& Spigel, B. (2017). Entrepreneurial ecosystems. In R. Blackburn, D. De Clercq, J. Heinonen, \& Z. Wang (Eds.) Handbook for entrepreneurship and small business (pp. 1-15). London: SAGE.

Sternberg, R. (2012). Do EU regional policies favour regional entrepreneurship? Empirical evidence from Spain and Germany. European Planning Studies, 20(4), 583-608.

Tervonen, T., \& Figueira, J. R. (2008). A survey on stochastic multicriteria acceptability analysis methods. Journal of Multi-Criteria Decision Analysis, 15, 1-14.

Tervonen, T., Linkov, I., Figueira, J. R., Steevens, J., Chappell, M., \& Merad, M. (2009). Risk-based classification system of nanomaterials. Journal of Nanoparticle Research, 11(4), 757-766.

Van de Ven, A. H. (1993). The development of an infrastructure for entrepreneurship. Journal of Business Venturing, 8, 211-230.

Van Praag, M. C. (1999). Some classic views on entrepreneurship. The Economist, 147(3), 311-335.

Verheul, I., Wennekers, S., Audretsch, D., \& Thurik, R. (2002). An eclectic theory of entrepreneurship: Policies, institutions and culture. In D. Audretsch, R. Thurik, I. Verheul, \& S. Wennekers (Eds.), Entrepreneurship: Determinants and policy in a European-US comparison. Dordrecht: Springer.

Von Bargen, P., Freedman, D., \& Pages, E. R. (2003). The rise of the entrepreneurial society. Economic Development Quarterly, 17(4), 315-323.

Wyrwich, M. (2012). Regional entrepreneurial heritage in a socialist and a post-socialist economy. Economic Geography, 88, 423-445.

World Economic Forum (2014). The Global Competitiveness Report 2013-2014, Klaus Schwab.

Zacharakis, A., Shepard, D., \& Coombs J. (2003). The development of venture-capital-backed internet companies: An ecosystem perspective. Journal of Business Venturing, 18, 217-231. 